OPEN ACCESS

Edited by:

Zhijun Yu,

Hebei Normal University, China

Reviewed by:

Fernando Diaz,

Ensenada Center for Scientific

Research and Higher Education

(CICESE), Mexico

Pavel Eduardo Galindo Torres,

Center for Biological Research of the

Northeast (CIBNOR), Mexico

Claudia Ventura-López,

Ensenada Center for Scientific

Research and Higher Education

(CICESE), Mexico

*Correspondence:

Shihao L

lishihao@qdio.ac.cn

Fuhua Li

fhli@qdio.ac.cn

Specialty section:

This article was submitted to

Invertebrate Physiology,

a section of the journa

Frontiers in Physiology

Received: 07 August 2019 Accepted: 04 December 2019 Published: 20 December 2019

Citation

Guo Q, Li S, Lv X, Xiang J, Manor R, Sagi A and Li F (2019) Sex-Biased CHHs and Their Putative Receptor Regulate the Expression

of IAG Gene in the Shrimp

Litopenaeus vannamei.

Front. Physiol. 10:1525.

doi: 10.3389/fphys.2019.01525

\section{Sex-Biased CHHs and Their Putative Receptor Regulate the Expression of IAG Gene in the Shrimp Litopenaeus vannamei}

\author{
Qing Guo ${ }^{1}$, Shihao Li ${ }^{1,2,3 *}$, Xinjia Lv ${ }^{1,4}$, Jianhai Xiang ${ }^{1,2}$, Rivka Manor $^{5}$, Amir Sagi ${ }^{5}$ and \\ Fuhua $L^{1,2,3 *}$
}

\footnotetext{
${ }^{1}$ Key Laboratory of Experimental Marine Biology, Institute of Oceanology, Chinese Academy of Sciences, Qingdao, China, ${ }^{2}$ Laboratory for Marine Biology and Biotechnology, Qingdao National Laboratory for Marine Science and Technology, Qingdao, China, ${ }^{3}$ Center for Ocean Mega-Science, Chinese Academy of Sciences, Qingdao, China, ${ }^{4}$ University of Chinese Academy of Sciences, Beijing, China, ${ }^{5}$ Department of Life Sciences and the National Institute for Biotechnology in the Negev, Ben-Gurion University of the Negev, Beersheba, Israel
}

The "eyestalk-androgenic gland (AG)-testis" endocrine axis is involved in male sexual differentiation of crustaceans. The insulin-like androgenic gland hormone (IAG), secreted from the $A G$, plays a central role in this axis, however key factors upstream the IAG are still poorly understood. Here, two crustacean hyperglycemic hormone $(\mathrm{CHH})$ genes $(L v C H H 1$ and $L v C H H 2)$ and their putative receptor guanylate cyclase ( $L v G C)$ were identified in Litopenaeus vannamei. $\mathrm{LvCHH} 1$ and $\mathrm{LvCHH} 2$ belonged to $\mathrm{CHH}$ subfamily I members and LVGC was a membrane-bound guanylate cyclase. They were all differentially expressed in eyestalks and gonads of males and females. RNA interference (RNAi) of either $\angle V C H H 1$ or $\angle V C H H 2$ increased $L V I A G$ expression, while injection of their recombinant protein decreased $L V I A G$ expression, indicating that $\mathrm{LVCHH} 1$ and $\mathrm{LVCHH} 2$ are inhibitory factors of $L V I A G$ expression. Yeast two-hybrid assay showed that both $\mathrm{LVCHH} 1$ and $\mathrm{LVCHH} 2$ interacted with LvGC and their RNAi and recombinant protein injection exerted opposite regulatory effects on the transcriptional expression of $\angle v G C$. Meanwhile, knockdown of $\angle v G C$ increased $L V I A G$ expression. These results suggest that LVGC is the receptor of $\mathrm{LVCHH} 1$ and $\mathrm{LVCHH} 2$ and they are all involved in male sexual development by regulating $L V I A G$ expression. The present study unveils missing upstream elements in the "eyestalk-AG-testis" endocrine axis in crustacean.

Keywords: $\mathrm{CHH}$, "eyestalk-AG-testis" endocrine axis, guanylate cyclase, IAG, male sexual differentiation

\section{INTRODUCTION}

In crustacean, sex determination and sexual differentiation, which lead to sexual dimorphism, attract an increasing attention. The androgenic gland (AG) unique to male crustaceans was first discovered in the blue crab Callinectes sapidus (Cronin, 1947). The function of the AG in regulating the male sexual differentiation has been confirmed in decapods such as Macrobrachium rosenbergii 
in which bilateral AG ablation led to the atrophy of the sperm ducts and testes (Sagi et al., 1990). In isopods, oogenesis was observed instead of spermatogenesis after removing the AG from male individuals, while gonadal masculinization and sex reversal were induced after AG implantation into female individuals (Suzuki and Yamasaki, 1997). The AG function was firstly identified in isopods to be mediated by a protein belonging to the insulin superfamily (Okuno et al., 1997, 1999). In decapods, insulin-like androgenic gland hormone (IAG) was firstly reported in Cherax quadricarinatus (Manor et al., 2007), and then it was reported in many decapod crustaceans (Banzai et al., 2011; Chung et al., 2011; Li et al., 2012; Lawrence et al., 2017) including Litopenaeus vannamei (LvIAG) (Vázquez-Islas et al., 2014). Knockdown of IAG by double-stranded RNA (dsRNA) mediated RNA interference (RNAi) could disrupt testis development and spermatogenesis in decapods (Ventura et al., 2009; Rosen et al., 2010), confirming that IAG secreted from the AG controls male sexual differentiation of crustaceans.

Eyestalk ablation leads to hypertrophy of the AG, change of its cell types and increase of RNA synthesis in AG cells of Pandalus platyceros (Foulks and Hoffman, 1974), C. quadricarinatus (Khalaila et al., 2002), and Portunus pelagicus (Sroyraya et al., 2010). In C. sapidus and Fenneropenaeus chinensis, eyestalk ablation significantly up-regulated the expression level of IAG (Chung et al., 2011) suggesting the existence of an "eyestalk-AG-testis" endocrine axis proposed to be involved in sexual differentiation of male crustaceans (Khalaila et al., 2002). As a major neuroendocrine structure specific to crustaceans, the X-organ/sinus-gland (XO-SG) complex located in crustacean eyestalk synthesizes and secretes neuropeptides that regulate various physiological processes, including regulation of carbohydrate metabolism, molting, growth, and reproduction (Santos and Keller, 1993; de Kleijn et al., 1994; Chung et al., 2010; Chang and Mykles, 2011). These functions are mainly performed by crustacean hyperglycemic hormones (CHHs), which are a large family of crustacean neurohormones synthesized in the medulla terminalis of the XO-SG (Lacombe et al., 1999).

Based on the preprohormone structure, $\mathrm{CHH}$ family neuropeptides can be divided into the subfamily I peptides containing a $\mathrm{CHH}$ precursor related peptide (CPRP) and the subfamily II peptides lack the CPRP (Böcking et al., 2002). The subfamily I peptides have been considered to play important role in the regulation of carbohydrate metabolism (Chung et al., 2010). In previous studies, the subfamily II peptides, including gonad/vitellogenesis-inhibiting hormone (GIH or VIH), moltinhibiting hormone $(\mathrm{MIH})$, and mandibular organ-inhibiting hormone $(\mathrm{MOIH})$, have been reported to regulate the gonad development and molting (Lacombe et al., 1999; Böcking et al., 2002). The inhibitory roles of GIH on ovary development were proposed in Homarus americanus (de Kleijn et al., 1994) and proven by silence of GIH expression and injection of GIH recombinant protein (Treerattrakool et al., 2008; Vrinda et al., 2017). In Metapenaeus ensis, one type of MIH, MIH-B, showed an inhibitory role in the initiation of vitellogenesis as its expression levels in the eyestalk decreased in the initial phase of ovary maturation ( $\mathrm{Gu}$ et al., 2002). A recent study revealed that $\mathrm{CHH}$ subfamily II members could also regulate male sexual development because silencing of either GIH or MIH could dramatically increase the transcriptional level of IAG in Macrobrachium nipponense (Li et al., 2015). Except for $\mathrm{CHH}$ family hormones, the crustacean female sex hormone in Scylla paramamosain was also found to be an inhibitory factor of IAG expression (Liu et al., 2018). These findings provide molecular evidence on the "eyestalk-AG-testis" endocrine axis hypothesis. However, most of the key factors upstream the IAG in the "eyestalk-AG-testis" endocrine axis, such as hormone receptor, were still poorly understood.

In the present study, two $\mathrm{CHH}$ subfamily I peptides ( $\mathrm{LvCHH} 1$ and $\mathrm{LvCHH} 2$ ) and their putative receptor, a guanylate cyclase (LvGC), were identified as part of the "eyestalk-AG-testis" endocrine axis in the Pacific whiteleg shrimp L. vannamei. Tissue distribution analysis showed that both LvCHHs and LvGC displayed sex-biased expression patterns. Functional analysis revealed that both $\mathrm{LvCHH} 1$ and $\mathrm{LvCHH} 2$ could interact with LvGC and regulate the expression of LvIAG.

\section{MATERIALS AND METHODS}

\section{Animals and Tissue Collection}

Ten adult L. vannamei, with a body length of $12.75 \pm 0.6 \mathrm{~cm}$, cultured in our lab, were reared in $8 \mathrm{~m}^{3}$ fiberglass with airpumped circulating sea water for 7 days before experiments. The water temperature was monitored regularly and maintained at $26^{\circ} \mathrm{C}$. The shrimps were fed with artificial diet twice a day. These shrimps, including five females and five males in the intermolt stage were used for sampling after 7 days culturing. The molting stages of used shrimp were determined according to the morphology described by Gao et al. (2015). The hemolymph was collected using a syringe preloaded with equal volume of sterilized pre-cooled anticoagulant solution $\left(115 \mathrm{mmol} \mathrm{L}^{-1}\right.$ glucose, $27 \mathrm{mmol} \mathrm{L}{ }^{-1}$ sodium citrate, $336 \mathrm{mmol} \mathrm{L}^{-1} \mathrm{NaCl}$, $9 \mathrm{mmol} \mathrm{L}{ }^{-1}$ EDTA $\cdot \mathrm{Na}_{2} \cdot 2 \mathrm{H}_{2} \mathrm{O}, \mathrm{pH}$ 7.4). The hemolymph from females and males was mixed as two samples, respectively. The hemocytes were isolated by an immediate centrifugation at $1000 \mathrm{~g}$ at $4^{\circ} \mathrm{C}$ for $15 \mathrm{~min}$ and preserved in liquid nitrogen. Fourteen tissues, including testis, ovary, gill, stomach, hepatopancreas, lymphoid organ (Oka), heart, intestine, epidermis, ventral nerve cord (VNC), brain, eyestalk (right side), thoracic ganglia (TG), and muscle were dissected. Each tissue from five female and five male shrimps were mixed, respectively. All collected samples were frozen in liquid nitrogen and then stored in $-80^{\circ} \mathrm{C}$ freezer for RNA extraction.

Eyestalk (left side) with the crust removed from five male shrimps were fixed in RNA friendly fixative (RFF) for 48 hours (h) at $4^{\circ} \mathrm{C}$. After dehydrating, clearing and embedding, the tissues were sliced into $5 \mu \mathrm{m}$ for hematoxilin and eosin (H\&E) staining and in situ hybridization.

\section{RNA Extraction and cDNA Synthesis}

Total RNAs were extracted using RNAiso Plus reagent (TaKaRa, Japan) according to the manufacturer's instructions. The quality 
and concentration of total RNAs extracted from different tissues were detected using $1.5 \%$ agarose electrophoresis and NanoDrop 2000 (Thermo Fisher Scientific, United States), respectively. The total RNA was pre-treated with DNase to eliminate genomic DNA and the cDNA was synthesized from $1 \mu \mathrm{g}$ total RNA with PrimeScript RT Reagent Kit (TaKaRa, Japan).

\section{Gene Cloning and Sequence Analysis}

The cDNA sequences of $L v C H H 1, L v C H H 2$ and $L v G C$, were obtained from an Illumina-based transcriptome sequencing database of $L$. vannamei constructed in our lab (Wei et al., 2014). Primers LvCHH1-F/R, LvCHH2-F/R, and LvGC-F/R were designed using Primer Premier 5 software $\left({ }^{1}\right.$ other primers were also designed with the software) to amplify the open reading frame (ORF) sequences of $\mathrm{LvCHH1}, \mathrm{LvCHH} 2$, and $L v G C$, respectively (Table $\mathbf{1}$ ). The PCR was performed using ExTaq (TaKaRa, Japan) as the following procedure: 1 cycle of denaturation at $95^{\circ} \mathrm{C}$ for $5 \mathrm{~min}, 40$ cycles of denaturation at $94^{\circ} \mathrm{C}$ for $30 \mathrm{~s}$, annealing at $56^{\circ} \mathrm{C}$ for $30 \mathrm{~s}$, and extension at $72^{\circ} \mathrm{C}$ for different times (30 s for $\mathrm{LvCHH} 1$ and $\mathrm{LvCHH} 2$, and $4 \mathrm{~min}$ for $L v G C$ ), followed by a cycle of extension at $72^{\circ} \mathrm{C}$ for $10 \mathrm{~min}$. The specific products were assessed by $1.5 \%$ agarose gel electrophoresis and purified using OMEGA Gel Extraction Kit (OMEGA, United States). The purified products were cloned into pMD19-T vector (TaKaRa, Japan) and transformed into Trans $5 \alpha$ competent cells. The selected positive clones with expected size of amplified $\mathrm{LvCHH} 1$ and $\mathrm{LvCHH} 2$ products were sent for DNA sequencing.

The complete ORF regions and deduced amino acid sequences of $\mathrm{LvCHH} 1, \mathrm{LvCHH} 2$, and $\mathrm{LvGC}$ were all analyzed using ORF finder ${ }^{2}$. Conserved protein domains were predicted with SMART $^{3}$. Multiple sequences alignments were performed by ClustalW and phylogenic analysis were constructed by the neighbor-joining (NJ) algorithm using the MEGA7 ${ }^{4}$. The reliability of the tree was tested by bootstrapping using 1,000 replications.

\section{PCR Detection on the mRNA Expression of LvCHHs and LvGC}

To detect the mRNA expression of $L v C H H s$ and $L v G C$ in both male and female individuals, primers LvCHH1-qF/qR, $\mathrm{LvCHH}-\mathrm{qF} / \mathrm{qR}$, and $L v G C-\mathrm{qF} / \mathrm{qR}$ (Table 1) were designed. Semiquantitative PCR was performed to detect the expression of $\mathrm{LvCHH} 1$ and $\mathrm{LvCHH} 2$ in all tissues following the program: denaturation at $94^{\circ} \mathrm{C}$ for $5 \mathrm{~min} ; 30$ cycles of denaturation at $94^{\circ} \mathrm{C}$ for $30 \mathrm{~s}$, annealing at $56^{\circ} \mathrm{C}$ for $30 \mathrm{~s}$ and extension at $72^{\circ} \mathrm{C}$ for $30 \mathrm{~s}$. The PCR products were assessed by electrophoresis on $1.5 \%$ agarose gel. The quantitative real-time PCR (qPCR) was performed to detect the expression of $L v C H H s$ and $L v G C$ on Eppendorf Mastercycler ${ }^{\circledR}$ ep realplex (Eppendorf, Germany) using Toyobo Thunderbird qPCR Mix (Toyobo, Japan). The

\footnotetext{
${ }^{1}$ www.premierbiosoft.com/primerdesign/

${ }^{2}$ https://www.ncbi.nlm.nih.gov/orffinder/

${ }^{3}$ http://smart.embl-heidelberg.de/

${ }^{4}$ https://megasoftware.net/
}

procedure under the condition described below: denaturation at $94^{\circ} \mathrm{C}$ for $1 \mathrm{~min}$; 40 cycles of $94^{\circ} \mathrm{C}$ for $20 \mathrm{~s}, 56^{\circ} \mathrm{C}$ for $20 \mathrm{~s}$, and $72^{\circ} \mathrm{C}$ for $20 \mathrm{~s}$. The specificity of PCR product was checked by melting curve followed the procedure: $95^{\circ} \mathrm{C}$ for $15 \mathrm{~s}, 60^{\circ} \mathrm{C}$ for $15 \mathrm{~s}, 95^{\circ} \mathrm{C}$ for $15 \mathrm{~s}$.

\section{In situ Hybridization Transcription of Digoxygenin (DIG)-Labeled Riboprobe}

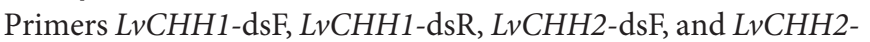
dsR (Table 1) were designed with a T7 promoter sequence at the $5^{\prime}$ end. The plasmids containing right sequences of $\mathrm{LvCHH1}$ and $\mathrm{LvCHH} 2$ obtained in Section "Gene Cloning and Sequence Analysis" were extracted using Plasmid Mini Kit I (Omega, United States) and used as the PCR templates for synthesis of sense and antisense RNA probes. The primers LvCHH1$\mathrm{dsF} / \mathrm{R}$ and $\mathrm{LvCHH} 1-\mathrm{F} / \mathrm{dsR}$ (Table 1) were used to amplify 577 bp $L v C H H 1$ fragments, which were used as the templates for synthesis of sense and antisense RNA probe of $\mathrm{LvCHH1}$, respectively. The primers $\mathrm{LvCHH} 2-\mathrm{dsF} / \mathrm{R}$ and $\mathrm{LvCHH} 2-\mathrm{F} / \mathrm{dsR}$ (Table 1) were used to amplify 439 bp $\mathrm{LvCHH} 2$ fragments, which were as the templates for synthesis of RNA probe of $\mathrm{LvCHH} 2$, respectively. The PCR program was performed as follows: denaturation at $95^{\circ} \mathrm{C}$ for $5 \mathrm{~min}, 40$ cycles of $94^{\circ} \mathrm{C}$ for $30 \mathrm{~s}$, $60^{\circ} \mathrm{C}$ for $30 \mathrm{~s}$, and $72^{\circ} \mathrm{C}$ for $30 \mathrm{~s}$, followed by a cycle of extension at $72^{\circ} \mathrm{C}$ for $10 \mathrm{~min}$. The PCR products were purified using MiniBEST DNA Fragment Purification Kit (TaKaRa, Japan). The purified PCR products were assessed by electrophoresis on $1.5 \%$ agarose gel and the concentration was measured by Nanodrop 2000 (Thermo Fisher Scientific, United States). DIGlabeled oligo-nucleotides probes were synthesized using $450 \mathrm{ng}$ DNA templates through in vitro transcription using DIG RNA Labeling Mixture (Roche, Germany) and TranscriptAid T7 High Yield Transcription Kit (Thermo Fisher Scientific, United States). After assessing the concentration and quality, the DIG-labeled RNA probes were stored at $-80^{\circ} \mathrm{C}$ for later use.

\section{In situ Hybridization}

Tissues were dehydrated in gradient ethanol and embedded in paraffin. Paraffin-embedded tissues were sectioned into slices of $5 \mu \mathrm{m}$, deparaffinized, and hydrated in DEPC treated water. After proteinase $\mathrm{K}(15 \mu \mathrm{g} / \mathrm{mL})$ treated at $37^{\circ} \mathrm{C}$ for $30 \mathrm{~min}$, tissues were washed with PBS for $10 \mathrm{~min}$ and fixed in $4 \%$ paraformaldehyde at $4^{\circ} \mathrm{C}$ for $5 \mathrm{~min}$. Then the sections were pre-incubated at $37^{\circ} \mathrm{C}$ for $3 \mathrm{~h}$ in the pre-hybridization buffer (50\% formamide deionized, $5 \times$ SSC, $1 \mu \mathrm{g} / \mu \mathrm{L}$ salmon sperm DNA, $10 \times$ Denhardt's). Hybridization was performed at $56^{\circ} \mathrm{C}$ overnight in $500 \mu \mathrm{L}$ hybridization solution for each sample following general protocol of DIG RNA labeling kit (Roche, Germany). The final concentration of both sense RNA probe and antisense RNA probe were $1 \mathrm{ng} \mu \mathrm{L}^{-1}$. After the hybridization, the slides were washed with $2 \times$ SSC for $2 \times 15$ min, $1 \times$ SSC for $2 \times 15 \mathrm{~min}$, and $0.1 \times$ SSC for $2 \times 15 \mathrm{~min}$. The hybridized probes were immunodetected with anti-digoxigenin-AP (1:500 dilution, Roche, Germany) at $4^{\circ} \mathrm{C}$ for $12 \mathrm{~h}$ and visualized by the color reaction using NBT/BCIP Stock Solution (Roche, 
TABLE 1 | Primer sequences and corresponding annealing temperature of genes.

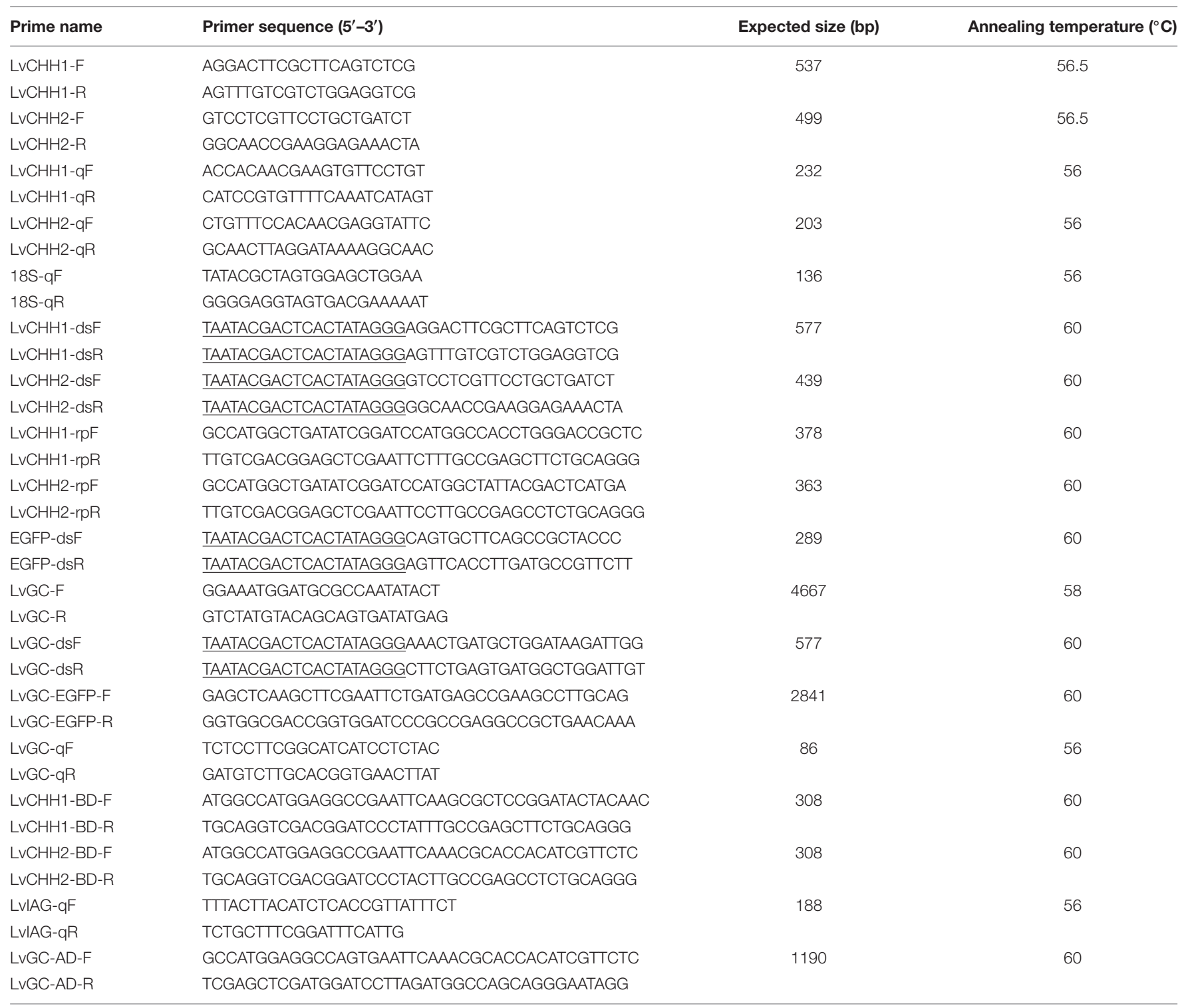

Germany). The final photos were captured by Nikon Eclipse $80 \mathrm{i}$ microscope (Nikon, Japan).

\section{Subcellular Localization of LvGC Protein in Mammalian 293T Cells}

To study the subcellular localization of LvGC, a plasmid containing the predicted signal peptide and transmembrane motif (TM) of LvGC was constructed, designed as pEGFPLvGC. The restriction endonucleases EcoRI and BamHI were used to generate linearized vector of pEGFP-N1. The nucleotide sequences which encoded the predicted signal peptide and TM domains were amplified using primers $L v G \mathrm{C}$-EGFP-F/R. Infusion HD Cloning Kit (Clontech, United States) was used to connect the linearized vector and the PCR product. The plasmid pEGFP-N1 was used as control plasmid. Two micrograms of the plasmids pEGFP-LvGC and pEGFP-N1 were transfected into the mammalian $293 \mathrm{~T}$ cells with Lipofectamine 3000 Reagent (Thermo Fisher Scientific, United States) following the manufacture's instruction, respectively. After $48 \mathrm{~h}$ culturing, the transfected cells were fixed with $4 \%$ paraformaldehyde, stained with $100 \mathrm{ng} / \mathrm{ml}$ DAPI (4', 6-diamidino-2-phenylindole) solution and washed with PBS. The green and blue fluorescence signals were acquired and merged through Nikon Eclipse Ti fluorescence microscope (Nikon, Japan).

\section{Unilateral Eyestalk Ablation and Detection on the Expression of LvIAG by Real-Time PCR}

As $\mathrm{L} v \mathrm{CHH} 1$ and $\mathrm{LvCHH} 2$ mainly expressed in male eyestalks (see section "PCR Detection on the mRNA Expression of LvCHHs and LvGC"), the transcripts of LvIAG after unilateral eyestalk ablation in adult male L. vannamei were detected to 


\section{A 1 GTAATTCCCTTTGCCTTGAGGACTTCGCTTCAGTCTCGTCCTCGCTTCGTGTGCCAGAC 60 ATGTTCGCGTCACGAATGGTGTGGTCAGCACTAGTGTTGTCTCTGATGGTGGCACTCGCA M $\quad$ F 120 GCCTCTGCCGCCACCTGGGACCGCTCCTTCCGCGATGAGGAAGAGCCGCCGAAGTTCCTG $\begin{array}{llllllllllllllllllll}\text { A } & S & A & A & T & \text { W } & \text { D } & R & \text { S } & \text { F } & R & \text { D } & \text { E } & \text { E } & \text { E } & \text { P } & \text { P } & K & F & \text { L }\end{array}$ \\ 180 CCTCCTTCTTCCCCCGACTCCTCTGCCGTGGCTCTCCCCAGGACCCTGCCTCTCCCCGCG $\begin{array}{llllllllllllllllllll}P & P & S & S & P & D & S & S & A & V & A & L & P & R & T & L & P & L & P & A\end{array}$ 240 GACGAGGACCACAGCCTCAGCAAGCGCTCCGGATACTACAACTCGTGCACGGGCGTCTAC $\begin{array}{lllllllllllllllllllll}\text { D } & \text { E } & \text { D } & \text { H } & \text { S } & \text { L } & S & K & R & S & G & Y & Y & N & S & C & T & G & V & Y\end{array}$ 300 GACCGCGAACTCATCGCCAGGCTCGACCGCGTGTGCGAGGACTGCTACAACCTCTACCGC $\begin{array}{llllllllllllllllllll}D & R & E & L & I & A & R & L & D & R & V & C & E & D & C & Y & N & L & Y & R\end{array}$ 360 GACGTCGAGGTGGCTGTGGGCTGCAGGAAAGGATGTTACCACAACGAAGTGTTCCTGTAC $\begin{array}{llllllllllllllllllll}\text { D } & V & \text { E } & \text { V } & A & \text { V } & G & \text { C } & R & \text { K } & G & \text { C } & \text { Y } & \text { H } & \text { N } & \text { E } & \text { V } & \text { F } & \text { L } & \text { Y }\end{array}$ \\ 420 TGCGTGGACTACATGTTCCGGCCTCGCCAAAGGAACCAGTACCGGGCCGCCCTGCAGAAG

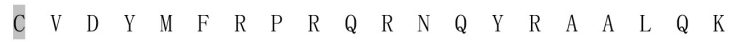 \\ 480 CTCGGCAAATAGGCGGTTCCTCTCCGGCCACACCTTCTGCAGCGACGCCCGCCTTGCGAC L $\quad \underline{G \quad K}$ \\ 540 CTCCAGACGACAAACTCTAGACTCTTCTTTGGTTCTCCTTATATTACCAAATGAATGGAA 600 CTCCAAACTATGATTTGAAAACACGGATGTTAAATATCGAAGCCGTC}

B 1 AATACCAACGGCCGCTTATATAAGGCGATGTTCTCTTGTGTCTGAGTCAGTGCAGAGAG 60 AGAGAGCTCGCAGGTCGCTGGTCCTCGTTCCTGCTGATCTGTGCCGAGTCCTGCGAAATG

\section{M}

120 GTTGCGGTGCAATTAGCTGTCTTAATGTGCATGCTGCTGGCAGTTCCGGCAGCTATTACG $\begin{array}{llllllllllllllllllll}V & \text { A } & \text { V } & \text { Q } & \text { L } & \text { A } & \text { V } & \text { L } & \text { M } & \text { C } & \text { M } & \text { L } & \text { L } & \text { A } & \text { V } & \text { P } & \text { A } & \text { A } & \text { I } & \text { T }\end{array}$

180 ACTCATGACAACACGAATGAATTACCGAAATTCCTTCTTTCCTCCCCTGGGGATTCTCTC $\begin{array}{llllllllllllllllllll}\mathrm{T} & \mathrm{H} & \mathrm{D} & \mathrm{N} & \mathrm{T} & \mathrm{N} & \mathrm{E} & \mathrm{L} & \mathrm{P} & \mathrm{K} & \mathrm{F} & \mathrm{L} & \mathrm{L} & \mathrm{S} & \mathrm{S} & \mathrm{P} & \mathrm{G} & \mathrm{D} & \mathrm{S} & \mathrm{L}\end{array}$

240 ACTTCGGGCCAAAGCTTAATCAAACGCACCACATCGTTCTCTTCTTGCACGGGCGTCTAC $\begin{array}{lllllllllllllllllllll}T & S & G & Q & S & L & I & K & R & T & T & S & F & S & S & C & T & G & V & Y\end{array}$

300 GACCGCGAGCTCCTTGCGAGGCTCGACCGCGTGTGCGAAGACTGCTACAACCTGTACCGC $\begin{array}{llllllllllllllllllll}\text { D } & R & E & L & L & A & R & L & D & R & V & C & E & D & C & Y & N & L & Y & R\end{array}$

360 GACGTCGGAGTGGCGGCCGAATGCAGGAGCAACTGTTTCCACAACGAGGTATTCCTGTAC $\begin{array}{llllllllllllllllllllllllll}\text { D } & \text { V } & G & \text { V } & \text { A } & \text { A } & \text { E } & \text { C } & \text { R } & \text { S } & \text { N } & \text { C } & \text { F } & \text { H } & \text { N } & \text { E } & \text { V } & \text { F } & \text { L } & \text { Y }\end{array}$

420 TGCGTCGACTACATGTACCGGCCTCGCCAAAGGAACCAGTACCGGGCCGCCCTGCAGAGG $\begin{array}{llllllllllllllllllllllllllll}C & V & D & Y & M & Y & R & P & R & Q & R & N & Q & Y & R & A & A & L & Q & R\end{array}$

480 CTCGGCAAGTAGGCGCTTCCTCTCCGGCCACACCTTCTCCGGCGACGCTCCCTGTGGGAC L $\quad \underline{G \quad K}$

540 TTTCTGAATGGCCAGACTCTAGTTTCTCCTTCGGTTGCCTTTTATCCTAAGTTGCAAGCT 600 GAGATCACACTGACGACG

C MSRSLAVLTCPVLVLAVLLCEAREMSRGASGRRPQHLRENELRSQEQGVLWSHEYSLNDGPSPLASSSFAALNSHARAARHRRTQPRGFDAFHTAPLPSSSNSPFAFSFNTTSR EDYSLEEKCSHEQFRDTVKRQKDYIDNYLTQSYNDSRENITIGFLSSFTYNKLALGALPLAVEDVNNDHNLLPGKRLVFEVADVGNSNLEALAALSIRRMTTMRDKGHLVFI GPDDNCANEALVAAAWNLPMITYKCADKRVSNKTKYYTFARTMPPSTKIVKALVSLLKVYSWRQFVLLTEHTRNYQQIKEAVKSFADHHKMNITRELSVPYDYTTSG YHTIQGFVRGTIRSTRIVVLVASYEVQWDFVLALREEAGDHLAEYAIVTIDDDKYNGGSETQVVRVPGKDKEMLNMSKETADRLYHGFRAVVKITPAFPTNKKYREFEK KVLNRIKQYPFCVPYNPGIFPFIEVPISAAHLYDAVMMYAKVLHETLANPYADPANGTHILSLIKNRSFPSIQGFKLHMDENADAEGSYSLLAIRQLSSDHTPPMGWHKV GHFHFHDHRTGSHDMDNLPTLVMNDTILWLGAGPPLDAPKCGFASEKCGTDWS LLGGGVLMLVMVAA FLCRHYRYEQRLACLLWKIDMREVTILNDPAKVPSHAPVN NNTNLLWGGVDGQLEVPRVSYCKMGVYKNNIVAVKPVKKRNVDLTRSIRKELQQMREVRHENLLPFIGASVDTGAVCVLTAYCTRGSLEDVLANDDFLLDNMFVASLVADLI KGMMFLHDSEIVSHGNLRSSNCLIDSRWVLMVADFGLHEFKASPEVVIEPRKRLWTAPELLRRGASLPRGTQKGDAFSFGIILYEVMGRKGPWGDYMDKFTVQDILSKLRECCE PPLRPPLDTLKAPEYVHRCLRECWVEEPDERPDFKLIQMRLKEMQAGLKLNIVDNMLAMMEKYAYNLEGKVQERTKQLMEEKKKTEILLLRMLPKSVAESLKRGEKVHPESY DNVTIYFSDIVGFTSLSATSTPLQMVDMLNDLYTCFDAIIGDYDVYKVETIGDAYMVVSGLPICNGDRHAGEIASMALKLLDAARTFTIRHRPSDTLKLRIGIHSGPCVA GVVGLTMPRYCLFGDTVNTASRMESTGEQLRIHISNANKLMLDKIGGYLVEKRGLTYVKGKGQMMTWWLVGVQRPDERDPDALGDSQATPTRTPVDESHPSTAHTPTS SAQPSSLAQSAAVSSASPSGHCLVGYGIPPPAAAPSPSRHDTLASPGATRGLASGSPGFAHAGLTNSSSFTHDIEVTHNQPLNQRPELTNSPSFTRDIEVGHNPAITQKTEARNS PSFTHDVEVTHTPALVHCSPRPRTPSHATQGSPVGPPPAPRPRDTERDPALAPDALAGGGGSRAASGISTADHRLPLFNSAGDISSVQNSLDVKPVQTPPCKAALEREARQEA AQAESRRAEDPQLATASPRPQRAPLTVDSAVVPLTSDVIQDLRNGSAVTLHYQPAPIAPNKQGSRKNFV

FIGURE 1 | Deduced amino acid sequences and predicted domains of $\mathrm{LVCHH} 1, \mathrm{LVCHH}$, and LVGC. (A) Deduced amino acid sequence and predicted domains of LvCHH1. (B) Deduced amino acid sequence and predicted domains of $\mathrm{LvCHH}$ 2. Signal peptide was showed with light gray box. The $\mathrm{CHH}$-precursor-related peptide was bolded. Dibasic residue cleavage signal (KR) was marked in the box. Amidation signal (GK) was bolded, italic and underline. The conversed cysteine residues were shown as italic with dark gray box. (C) Deduced amino acid sequence and predicted domains of LVGC. Signal peptide was showed in light gray. The receptor domain was bolded and underlined. The transmembrane domain marked in the box. The protein kinase-like domain was showed in dark gray. The guanylate cyclase catalytic domain was bolded and italic. The primers used in RNAi were double underlined.

study whether LvCHHs could regulate the expression of LvIAG. Twenty male shrimp at inter-molt stage, equally divided into experimental group and control group, were temporarily reared in $8 \mathrm{~m}^{3}$ fiberglass with air-pumped circulating sea water for 7 days before experiments. The temperature of water was monitored to maintain at $26^{\circ} \mathrm{C}$. Unilateral eyestalk of each shrimp in the experimental group was ablated using hot tweezers. No eyestalk was ablated in the individuals from the control group. At 7 days after ablation, AGs were dissected from nine males at intermolt stage and mixed as three biological replications $(n=3,3$, 3) to detect the mRNA expression of LvIAG. The total RNAs extraction and CDNA synthesis were performed as described in Section "RNA Extraction and cDNA Synthesis". SYBR Greenbased quantitative real-time PCR (qPCR) was performed using designed primers $L v I A G-\mathrm{qF} / \mathrm{qR}$ and $18 \mathrm{~S}-\mathrm{qF} / \mathrm{qR}$ (Table 1). The procedure was running on Eppendorf Mastercycler ${ }^{\circledR}$ ep realplex (Eppendorf, Germany) using SuperReal PreMix Plus (SYBR Green) (Toyobo, Japan) under the process described below: denaturation at $94^{\circ} \mathrm{C}$ for $1 \mathrm{~min} ; 40$ cycles of $94^{\circ} \mathrm{C}$ for $20 \mathrm{~s}, 56^{\circ} \mathrm{C}$ for $20 \mathrm{~s}$, and $72^{\circ} \mathrm{C}$ for $20 \mathrm{~s}$.

\section{Preparation of Double-Stranded RNA (dsRNA) and Optimization of dsRNA Dosage}

Primers $L v C H H 1$-dsF/dsR, $L v C H H 2$-dsF/dsR, and $L v G C$-dsF/dsR (Table 1), were designed to amplify cDNA fragments as the templates for dsRNA synthesis of $L v C H H 1, L v C H H 2$, and $L v G C$, respectively. Primers of EGFP-dsF/dsR (Table 1) were used to amplify the template DNA fragments of enhanced green fluorescent protein (EGFP) gene for dsRNA synthesis. The PCR was performed as the following procedure: 1 cycle of denaturation at $95^{\circ} \mathrm{C}$ for $5 \mathrm{~min}, 40$ cycles of denaturation at $94^{\circ} \mathrm{C}$ for $30 \mathrm{~s}$, annealing at $60^{\circ} \mathrm{C}$ for $30 \mathrm{~s}$, and extension at $72^{\circ} \mathrm{C}$ for $30 \mathrm{~s}$, followed by an extension at $72^{\circ} \mathrm{C}$ for $10 \mathrm{~min}$. The specific products were purified and 


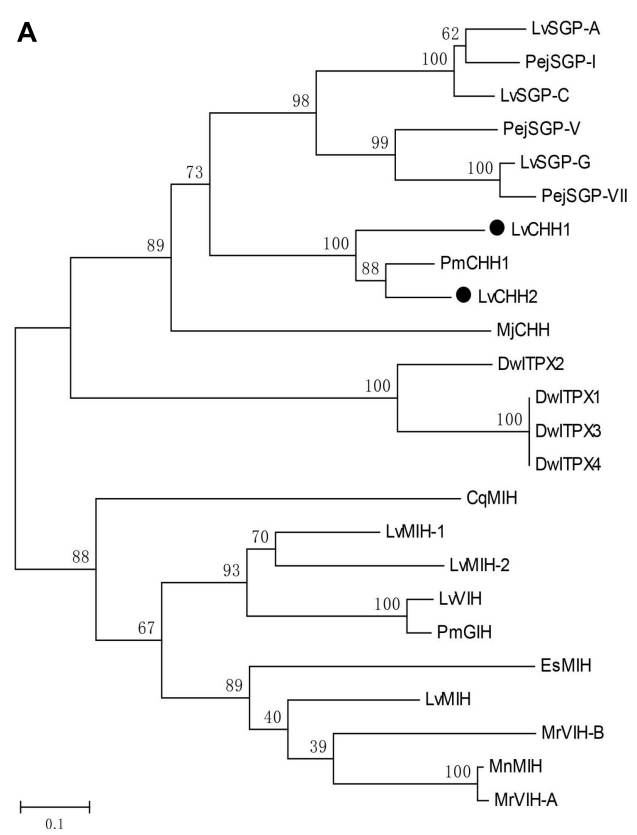

B

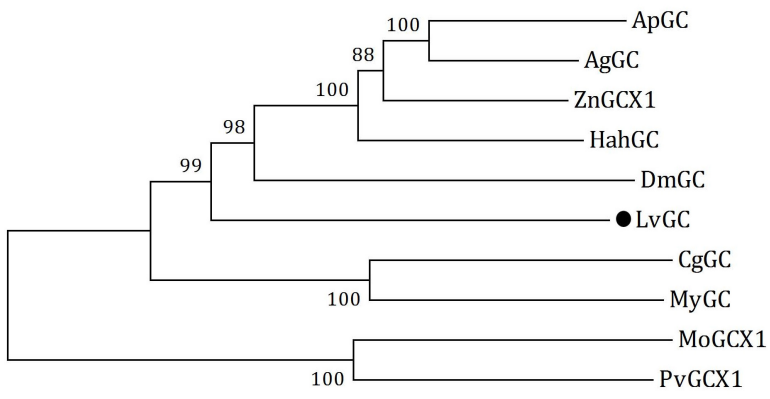

0.1

FIGURE 2 | Phylogenetic analyses of CHHs and GCs. (A) Phylogenetic analysis of LvCHH1 and LvCHH2 (solid circle) from Litopenaeus vannamei and homologous proteins from other species (Drosophila willistoni, DwITPX1/XP_015034465, DwITPX2/XP_015034467, DwITPX3/XP_002062858, DwITPX4/XP_023037604; Penaeus japonicus, PejSGP-I/BAA22560, PejSGP-V/BAA22561, PejSGP-VII/BAA22562; Marsupenaeus japonicus, MjCHH/BAE78493; P. monodon, PmCHH1/AAQ24525, PmGIH/AMQ67879; C. quadricarinatus, CqMIH/ACX55057; Eriocheir sinensis, EsMIH/ABC68517; M. nipponense, MnMIH/AIP90070; M. rosenbergii, MrVIH-A/AAL37948, MrVIH-B/AAL37949; L. vannamei, LvSGP-A/BBA57870.1, LvSGP-C/BBA57874.1 LvSGP-G/BBA57873, LVMIH/ATN45407, LvMlH-1/ABD73291, LvMIH-2/ABD73292, LvVIH/AGX26044). (B) Phylogenetic analysis of LvGC (solid circle) from L. vannamei and homologous proteins from other species (Agrilus planipennis, ApGC/XP_025832416; Anoplophora glabripennis, AgGC/XP_023312344; Zootermopsis nevadensis, ZnX1/XP_021915041; Halyomorpha halys, HahGC/XP_014284869; Daphnia magna, DmGC/KZS20192; Crassostrea gigas, CgGC/EKC28433; Mizuhopecten yessoensis, MyGC/OWF46460; Microtus ochrogaster, MoGCX1/XP_005362150; Pogona vitticeps, PvGCX1/XP_020666428). Bootstraps were performed with 1000 replicates to ensure reliability.

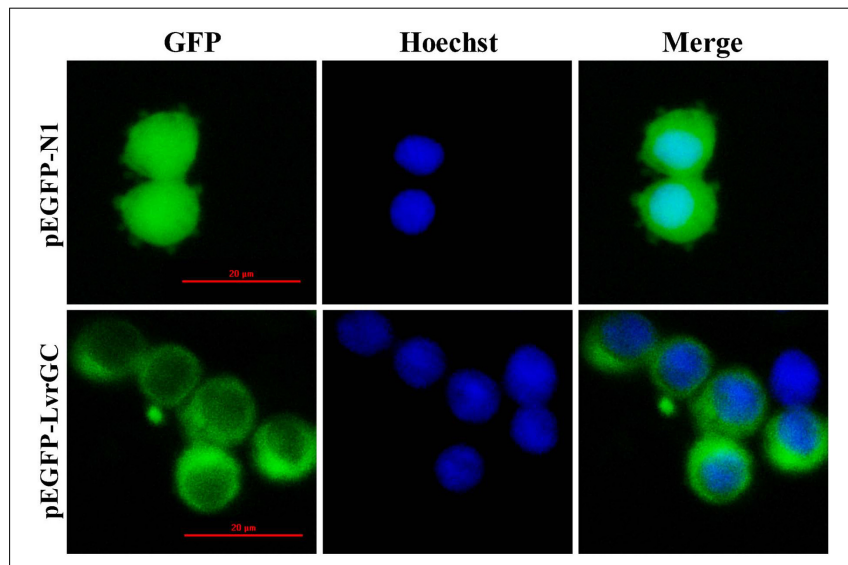

FIGURE 3 | Location of LVGC in HEK293. GFP showed the observation excited by blue light. Hoechst showed the observation excited by green light. Merge showed the merged observation excited by blue light and green light.

assessed. The dsRNAs were synthesized with $1 \mu \mathrm{g}$ template DNA using TranscriptAid T7 High Yield Transcription Kit (Thermo Fisher Scientific, United States). After RNaseA (Thermo Fisher Scientific, United States) digesting, synthesized dsRNAs
(dsCHH1, dsCHH2, dsGC, and dsEGFP) were assessed on 1.5\% agarose gel, and the concentration was measured by Nanodrop 2000 (Thermo Fisher Scientific, United States) and stored at $-80^{\circ} \mathrm{C}$ until use.

Forty-eight male L. vannamei, with a body length of $12.5 \pm 0.6 \mathrm{~cm}$ and a body weight of $25.4 \pm 1.3 \mathrm{~g}$, were chosen to optimize the dosage of dsRNAs, dsCHH1, dsCHH2, dsGC, and dsEGFP. Each group contained four individuals. The efficiency of dsRNAs was detected under different injection dosages, including 1, 2, $4 \mu \mathrm{g}$ for each shrimp. The same dosage of dsEGFP was injected into control group corresponding to the experiment group. The dsRNA was intramuscularly injected into each individual at the $5^{\text {th }}$ abdominal segment. Eyestalks of four individuals were sampled after $48 \mathrm{~h}$ after injection with dsCHH1, dsCHH2, dsGC, and dsEGFP, respectively. Total RNA extraction and cDNA synthesis were the same as described in Section "RNA Extraction and cDNA Synthesis."

\section{Detection on the Transcription Level of LvIAG and LvGC After RNAi}

After optimization, $2 \mu \mathrm{g}$ was chosen for dsCHH1 and dsGC and $4 \mu \mathrm{g}$ was chosen for dsCHH2 to inject into each shrimp, respectively. The same dosage of dsEGFP was injected into control group corresponding to the experiment group. After $48 \mathrm{~h}$, 


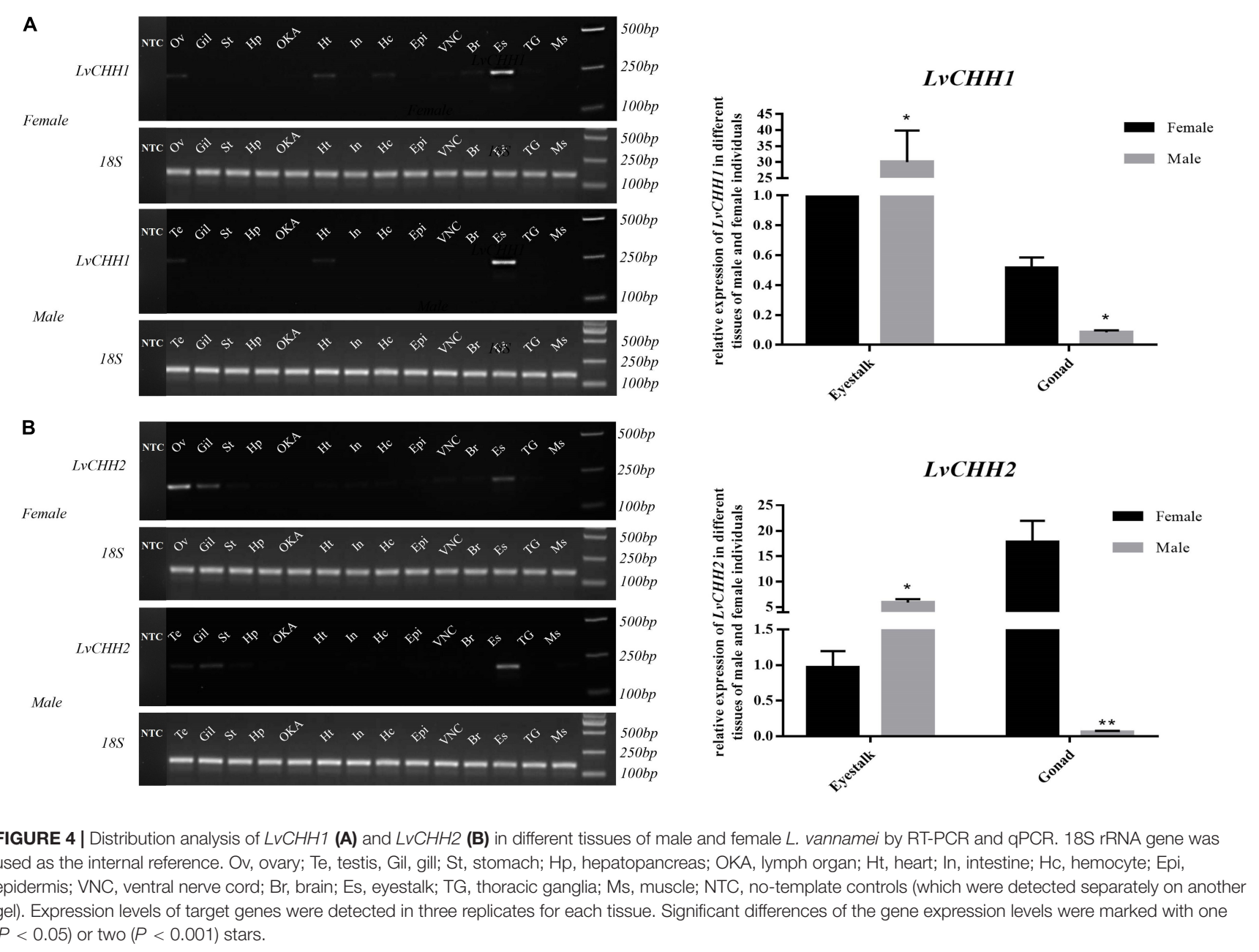

the AGs were sampled to detect the relative expression of LvIAG. At the same time, the cephalothorax and eyestalks were collected to analyze the effects of $\mathrm{LvCHH} 1, \mathrm{LvCHH} 2$ knockdown on the expression regulation of $L v G C$. Primers (Table 1) used in qPCR were performed as described in Sections "PCR Detection on the mRNA Expression of LvCHHs and LvGC" and "Unilateral Eyestalk Ablation and Detection on the Expression of LvIAG by Real-Time PCR."

\section{Expression and Purification of Recombinant Protein}

Endonucleases EcoRI and BamHI were used to linearize the plasmid pET30a. Primers LvCHH1-rpF/rpR, LvCHH2-rpF/rpR were designed with $15 \mathrm{bp}$ extension homologous of linearized pET30a vector (Novogen, France) ends at both ends to amply the ORF of LvCHH1 and LvCHH2 excluding sequence encoding signal peptide, respectively. The PCR products were purified and inserted into the linearized pET30a using in-fusion cloning reaction with In-fusion HD Cloning Kit (Clontech, United States). The recombinant plasmids, pET30a-CHH1 and pET30a-CHH2, were transformed into E. coli BL21 (DE3) competent cell for sequencing.
The recombinant proteins successfully expressed in the inclusion bodies of E. coli. $\mathrm{rCHH} 1$ and $\mathrm{rCHH} 2$ were purified with a gradient urea of 3 and $5 \mathrm{M}$, and dissolved in $8 \mathrm{M}$ urea and refolded by gradient dialysis. These recombinant proteins were examined by SDS polyacrylamide gel electrophoresis (SDSPAGE) and quantified to concentration of $500 \mathrm{ng} \mu \mathrm{L}^{-1}$ by BCA Protein Assay Kit (Tiangen, Beijing) for use.

\section{Detection on the Transcription Level of LvIAG and LvGC After Recombinant Proteins Injection}

Twelve experimental animals were divided into three groups. Each experimental group was injected with $5 \mu \mathrm{g} \mathrm{rCHH} 1, \mathrm{rCHH} 2$ dissolved in $20 \mu \mathrm{L}$ PBS, respectively. Control group was injected with $20 \mu \mathrm{L}$ PBS. These shrimps were reared in fiberglass provided with continuous aeration for $24 \mathrm{~h}$. The temperature of water was maintained at $26^{\circ} \mathrm{C}$. After $24 \mathrm{~h}, \mathrm{AGs}$, cephalothorax and eyestalks of four individuals were sampled. The Total RNAs extraction and cDNA synthesis were performed following the procedures in Section "RNA Extraction and cDNA Synthesis." Real time PCR analysis with primers $L v I A G-\mathrm{qF} / \mathrm{qR}$ and $L v G C-\mathrm{qF} / \mathrm{qR}$ (Table 1) were performed as described in Section "Unilateral 
A

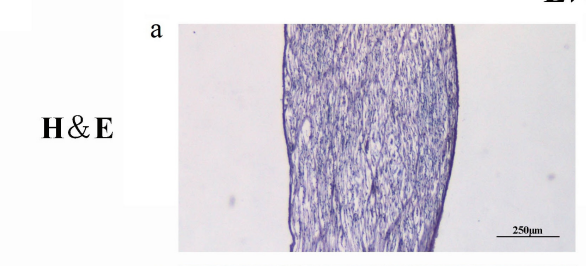

b

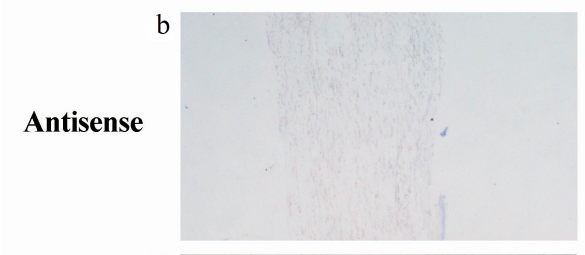

$\mathrm{c}$

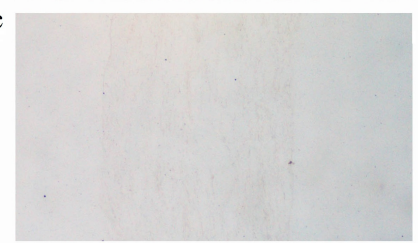

\section{$\mathrm{LvCHH1}$}

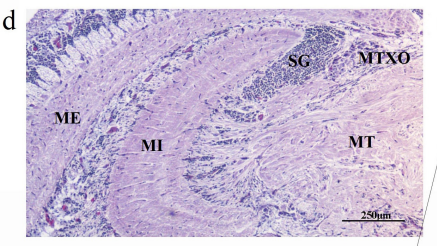

e

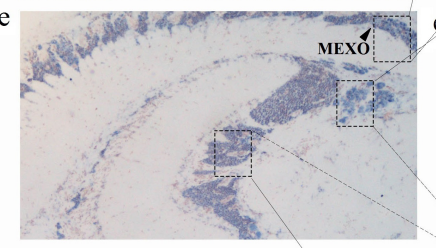

f

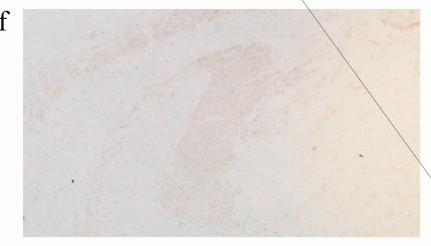

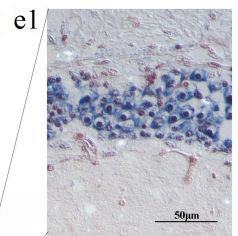

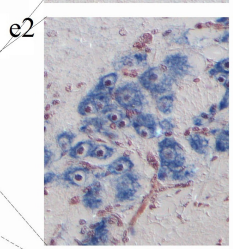

e3

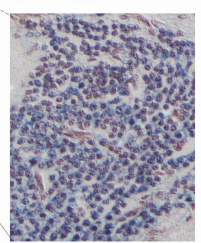

B

\section{$\mathrm{LvCHH2}$}
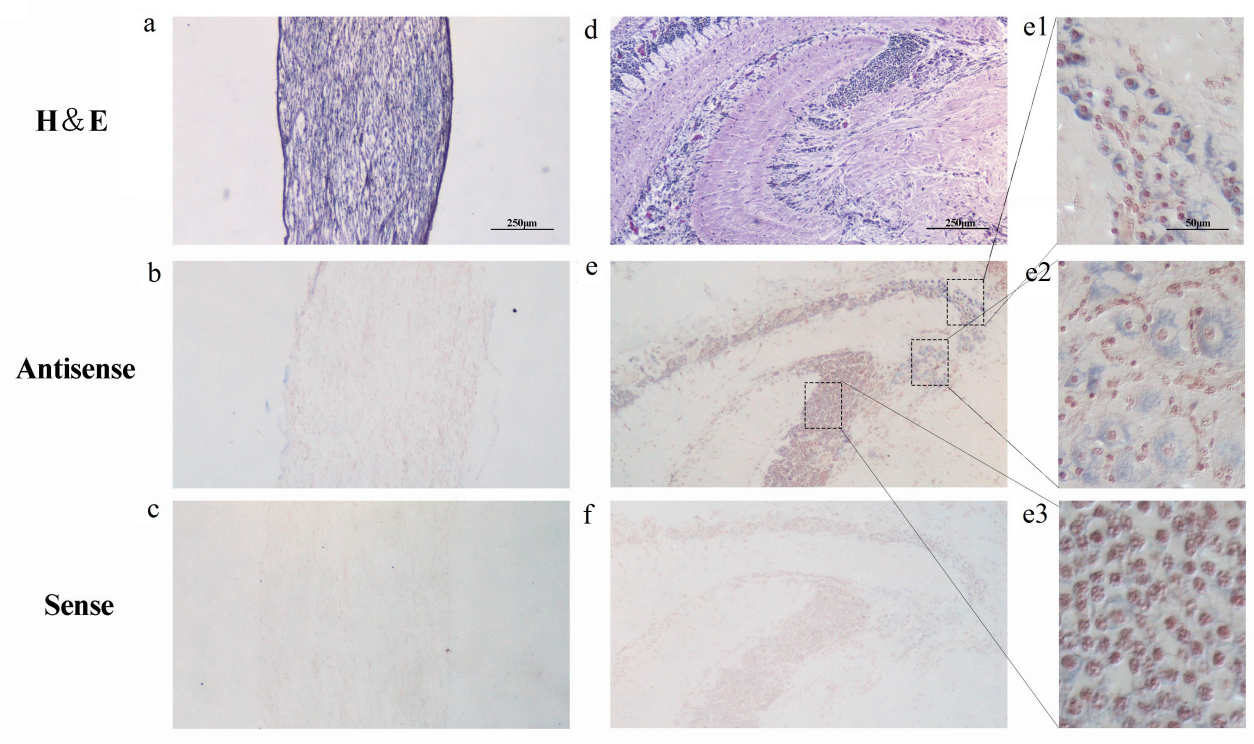

e3

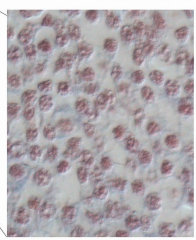

FIGURE 5 | Localization of $L v C H H 1$ (A) and $L v C H H 2$ (B) transcripts in the eyestalk of $L$. vannamei. Hematoxylin-Eosin (H\&E) staining (a,d) and sense probe (c,f) were used as controls of the antisense probe hybridization (b,e). Partial picture was enlarged into e1 (MEXO), e2 (MTXO), and e3 (SG). MTXO, medulla terminalis X-organ; MEXO, medulla externa X-organ; SG, sinus gland; MI, medulla interna; ME, medulla externa; MT, medulla terminalis.

Eyestalk Ablation and Detection on the Expression of LvIAG by Real-Time PCR.”

\section{Yeast Two-Hybrid Assay}

To further study the relation between the LvCHHs and LvGC, yeast two-hybrid system was performed. Plasmids, pGADT7 and pGBKT7 (TaKaRa, Japan), were digested with restriction endonucleases EcoRI and BamHI to generate linearized vectors. The nucleotide sequences encoding the mature peptide of LvCHHs and the extracellular domain of LvGC were amplified using primers $L v C H H 1-B D-F / R, L v C H H 2-B D-F / R$, and $L v G C-\mathrm{AD}-\mathrm{F} / \mathrm{R}$ (Table 1). The expression vectors were constructed as described in Section "Subcellular Localization of LvGC Protein in Mammalian 293T Cells." The plasmids combinations LvCHH1 with LvGC, LvCHH2 with LvGC were co-transformed into yeast strain $\mathrm{Y} 2 \mathrm{H}$ Gold by the lithium acetate transformation procedure following the Matchmaker protocol manual (Clontech, United States). The plasmids combination, pGBK-p53 with pGAD-T-antigen, was used for positive control and the combination pGBK-Lam and pGAD-T-antigen was used for negative control. After culturing on SD/-Leu/-Trp (DDO) plates, growing 3-5 days at $30^{\circ} \mathrm{C}$, all clones growing were 


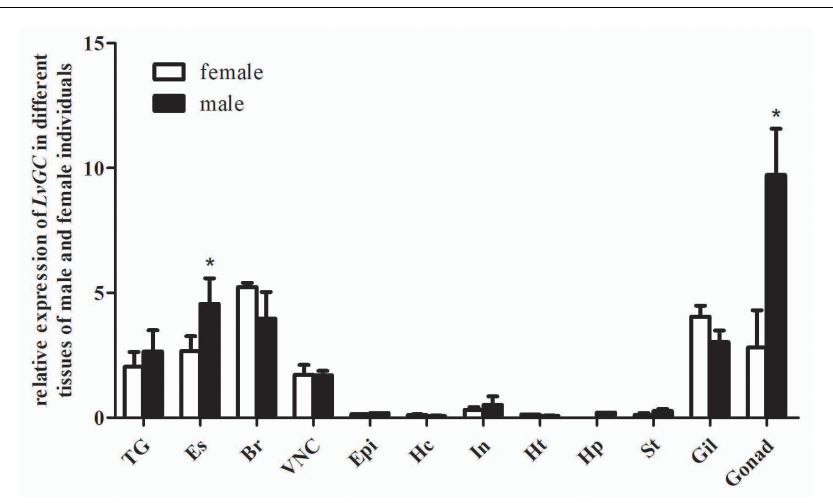

FIGURE 6 | Distribution of $\angle v G C$ in different tissues of male and female L. vannamei. 18S rRNA gene was used as the internal reference. TG, thoracic ganglia; Es, eyestalk; Br, brain; VNC, ventral nerve cord; Epi, epidermis; Hc, hemocyte; In, intestine; Ht, heart; Hp, hepatopancreas; St, stomach; Gil, gill; Ov, ovary; Te, testis. Expression levels of target genes were detected in three replicates for each tissue. Significant differences $(P<0.05)$ of $L v G C$ expression in male and female tissues were shown with stars $\left(^{*}\right)$.

collected and coated on SD/-Leu/-Trp/-His/-Ade/X- $\alpha$-gal/Aba (QDO/X/A) plates to perform $\beta$-Galactosidase activity analysis.

\section{Data Analysis}

In all qPCR experiments, each sample was set four technical replications. The relative expression level of $\mathrm{LvCHH1}$, $L v C H H 2, L v G C$, and $L v I A G$ were all calculated using the comparative $\mathrm{Ct}$ method with the formula $2^{-\Delta \Delta \mathrm{Ct}}$. Statistical analysis used unpaired two tailed $t$-test and Tukey multiple comparison test and performed by GraphPad Prism software (version 5.0). The $P$-value less than 0.05 was considered statistically significant.

\section{RESULTS}

\section{LvCHH1 and LvCHH2 Are CHH Subfamily I Members}

The ORF of $L v C H H 1$ (Accession number: MK732901) was 432 bp in length, encoding 143 amino acid residues, and the ORF of LvCHH2 (Accession number: MK732902) was 375 bp in length, encoding 124 amino acid residues. Both LvCHH1 and LvCHH2 belonged to $\mathrm{CHH}$ subfamily I. LvCHH1 is composed of a 23 aa signal peptide, a 44 aa $\mathrm{CHH}$-precursor-related peptide (CPRP) and a 76 aa mature protein (Figure 1A). LvCHH2 is composed of an 18 aa signal peptide, a 30 aa CPRP, and a 76 aa mature protein (Figure 1B). A processing signal $\mathrm{KR}$ and an amidation signal GK were found in both LvCHH1 and $\mathrm{LvCHH} 2$.

Phylogenetic analysis showed that LvCHH2 were first clustered with $\mathrm{CHH}$ from Penaeus monodon and then clustered with LvCHH1. They were all clustered together with other type I CHHs from L. vannamei and Marsupenaeus japonicus. In addition, the neuropeptides from $\mathrm{CHH}$ subfamily II were all clustered into another branch (Figure 2A).

\section{LvGC Is a Membrane-Bound Guanylate Cyclase}

Several partial transcripts encoding LvGC were obtained from the transcriptome above-mentioned (Wei et al., 2014). The whole transcript of LvGC was gained after PCR amplification and sequencing. The ORF of $L v G C$ was 4,551 bp (Accession number: MK732903) encoding 1,516 aa residues (Figure 1C). The deduced amino acid sequence of LvGC contained the conserved domains of guanylate cyclase family members, including signal peptide $\left(\mathrm{Met}^{1}-\mathrm{Ala}^{22}\right)$, a ligand binding domain $\left(\mathrm{Leu}^{167}-\mathrm{Ile}^{536}\right)$, a transmembrane domain $\left(\mathrm{Leu}^{607}\right.$ - $\mathrm{Leu}^{622}$ ), a protein kinase-like domain $\left(\mathrm{Val}^{681}\right.$ - Leu $\left.{ }^{929}\right)$ and a guanylate cyclase catalytic domain $\left(\mathrm{Glu}^{968}{ }_{\text {-Lys }}{ }^{1162}\right)$. Phylogenetic analysis showed that LvGC was first clustered together with GC from Limulus polyphemus, and then with members from insects (Figure 2B).

The predicted sequence encoding the transmembrane region of LvGC was sub-cloned into the plasmid pEGFP-N1 and transfected into 293T cells. Subcellular localization analysis revealed that the fluorescence signals expressed by constructed plasmid pEGFP-LvGC were mainly detected on the cell membrane of $293 \mathrm{~T}$ cells, while the fluorescence signals expressed by the control plasmid pEGFP-N1 were in the cytoplasm of 293T cells (Figure 3). The result confirms that LvGC is a membranebound guanylyl cyclase.

\section{Both LvCHHs and LvGC Show Sex-Biased Expression Patterns}

Tissue distribution and in situ hybridization analyses of $\mathrm{LvCHHs}$ and $L v G C$ were performed to detect whether they were involved in sexual development. Both $\mathrm{LvCHH1}$ and $\mathrm{LvCHH} 2$ transcripts were mainly detected in the eyestalk. The transcripts of both $\mathrm{LvCHH} 1$ and $\mathrm{LvCHH} 2$ were apparently higher in male eyestalks than those in female ones (Figure 4). Meanwhile, $\mathrm{LvCHH} 2$ was apparently detected in ovary and was higher thant that in testis (Figure 4B). In situ hybridization analysis of eyestalk showed that the transcripts of both $\mathrm{LvCHH1}$ (Figure 5A) and $\mathrm{LvCHH} 2$ (Figure 5B) were located in the secretory cells of the medulla terminalis X-organ (MTXO), medulla externa X-organ (MEXO) and sinus gland (SG). The expression profile of $L v G C$ was shown in Figure 6. The transcripts of $L v G C$ were mainly detected in gonads, eyestalk, gill and nerve system in both male and female individuals. However, there was no expression of $L v G C$ in AG tissue (with a Ct value more than 36 in the qPCR analysis results). In gonads and eyestalk, $L v G C$ showed significantly higher expression level in males than that in females. These data revealed that both $L v C H H s$ and $L v G C$ showed sex-biased expression patterns, indicating their involvement in sexual development.

\section{LvCHH1 and LvCHH2 Are Inhibitory Factors of LvIAG Expression}

After 7 days unilateral eyestalk ablation, the expression level of LvIAG was significantly increased by $180 \%$ when compared to that in the control shrimp (Figure 7A). DsRNA-mediated RNA interference of $\mathrm{LvCHH} 1$ and $\mathrm{LvCHH} 2$ achieved similar results. After knockdown the expression level of $\mathrm{LvCHH1}$ was reduced 
A

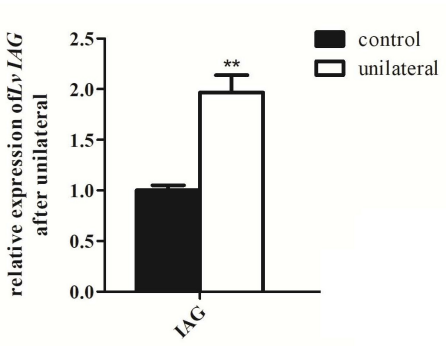

D

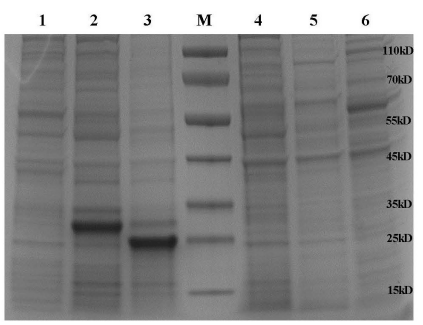

E

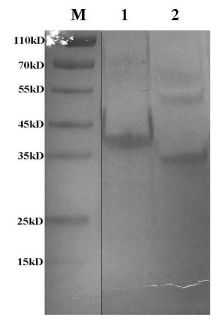

B

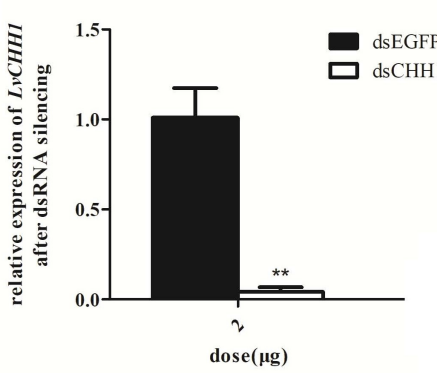

C

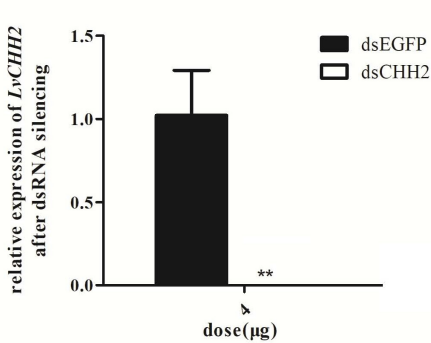

$\mathbf{F}$

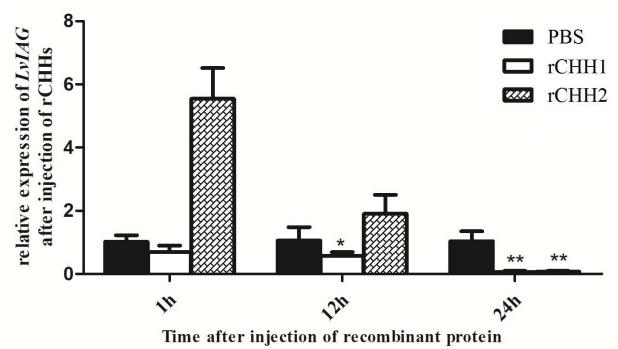

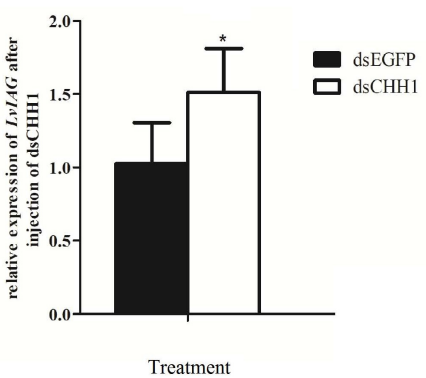

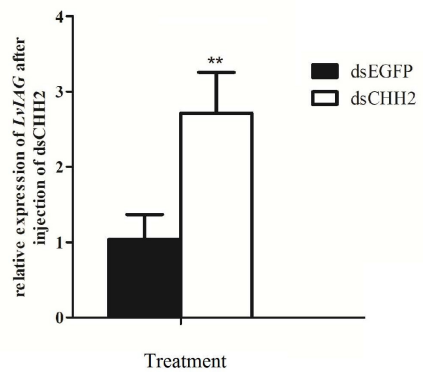

Treatment

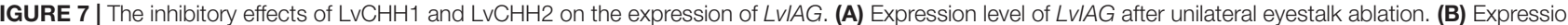
levels of $\angle V I A G$ after $\angle V C H H 1$ knockdown. (C) Expression levels of $L V I A G$ after $\angle V C H H 2$ knockdown. dsEGFP, injected with dsEGFP; dsCHH1, injected with dsCHH1; dsCHH2, injected with dsCHH2. (D) The recombination proteins of LvCHHs. 1-3, inclusion body; 1, pET30a; 2, rCHH1; 3, rCHH2; 4-6, supernatant; 4, pET3Oa; $5, \mathrm{rCHH}$; 6, $\mathrm{rCHH}$; $\mathrm{M}$, protein ladder. (E) The recombination proteins of $\mathrm{LvCHHs}$ after purification and refolding. 1, $\mathrm{rCHH} 1 ; 2, \mathrm{rCHH}$; $\mathrm{M}$, protein ladder. (F) Expression levels of $\angle v \mid A G$ after injection with $r C H H 1$ and $r C H H 2$. PBS, injected with PBS; $r C H H 1$, injected with $r C H H 1$; $r \mathrm{CHH}$, injected with $r C H H 2$. Expression levels of target genes were detected in three replicates. Significant differences of the gene expression levels between two treatments were shown with a star $(*)$ at $P<0.05$ or two stars $(* *)$ at $P<0.01$. by $96 \%$ while the expression level of $L v I A G$ increased by $147.6 \%$ when compared to that in control shrimp (Figure 7B). After knockdown the expression level of $\mathrm{LvCHH} 2$ was reduced by $99 \%$ while the expression level of LvIAG increased by $260 \%$ when compared to that in control shrimp (Figure 7C). The results showed that knockdown of either $\mathrm{LvCHH} 1$ or $\mathrm{LvCHH} 2$ increased the expression of LvIAG.

Recombinant LvCHH1 (rCHH1) protein or LvCHH2 ( $\mathrm{rCHH} 2)$ protein was injected into shrimp to study their effects on inhibiting LvIAG expression. The E. coli expressed $\mathrm{rCH} 1$ and $\mathrm{rCHH} 2$ were in inclusion bodies with distinct bands on SDS-PAGE at weight of 30 and $25 \mathrm{kDa}$, which were consisted with the predicted molecular weight of them (Figure 7D). The $\mathrm{rCHH} 1$ and $\mathrm{rCHH} 2$ proteins in inclusion bodies were dissolved and refolded with a gradient of urea solutions and then obtained the purified $\mathrm{rCHH} 1$ and $\mathrm{rCHH} 2$ proteins (Figure 7E). After injecting $\mathrm{rCHH} 1$ or $\mathrm{rCHH} 2$ proteins for $24 \mathrm{~h}$, the expression levels of $L v I A G$ were significantly decrease by 94 and $92 \%$, respectively (Figure $7 \mathbf{F}$ ). The results showed that injection of either recombinant $\mathrm{LvCHH} 1$ or $\mathrm{LvCHH} 2$ could inhibit the expression of $L v I A G$.

\section{LvGC Is a Putative Receptor of LvCHH1 and LvCHH2 and Inhibits LvIAG Expression}

As LvGC was found to be a membrane-bound guanylyl cyclase and showed similar sex-biased expression patterns with LvCHH1 and $\mathrm{LvCHH} 2$, further studies were performed to detect whether LvGC was the receptor of $\mathrm{LvCHH} 1$ and $\mathrm{LvCHH} 2$. Firstly, the transcriptional level of $L v G C$ was detected after $L v C H H 1$ or $\mathrm{LvCHH} 2$ silencing. When the expression levels of $\mathrm{LvCHH} 1$ and LvCHH2 were knocked-down by $96 \%$ (Figure 7B, left) and 99\% (Figure 7C, left), the transcriptional levels of $L v G C$ were 
A
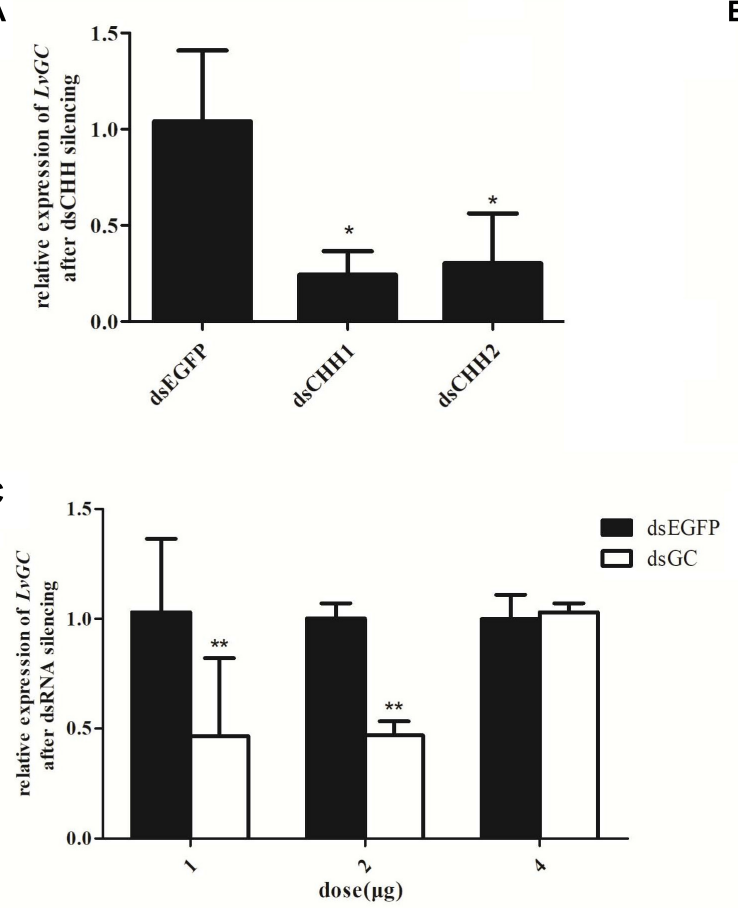

B

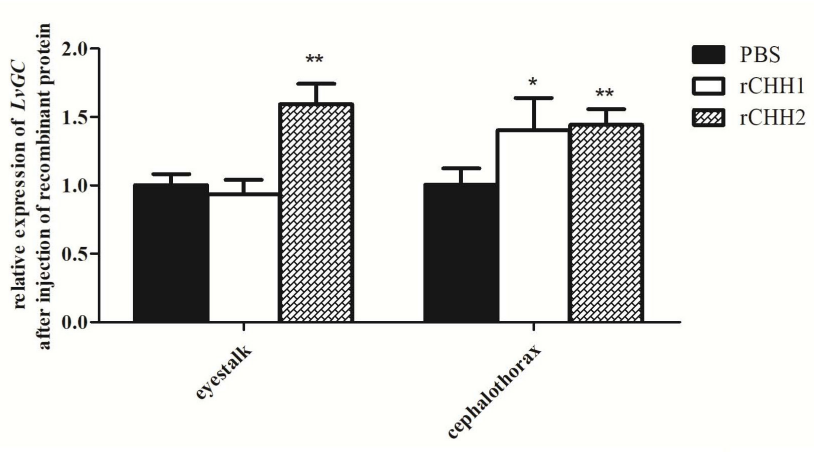

D

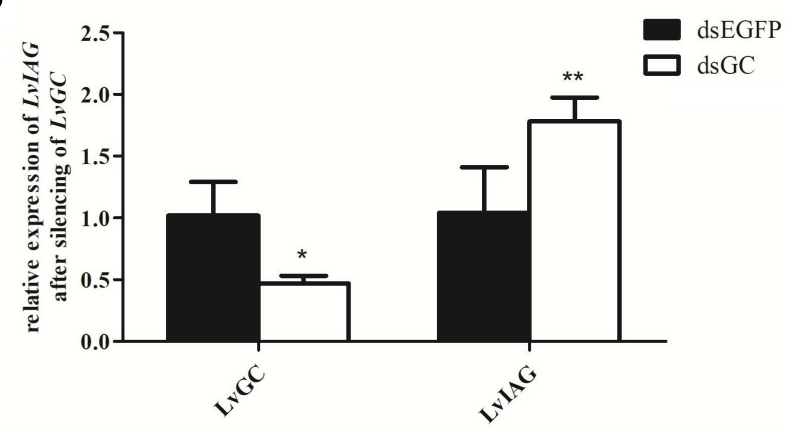

FIGURE 8 | Expression relationships among LvGC, LvCHHs, and LvIAG. Expression levels of LvGC after LvCHHs knockdown or recombinant protein injection. (A) The expression level of $L v G C$ after $L v C H H s$ knockdown. dsEGFP, injected with dsEGFP; dsCHH1, injected with dsCHH1; dsCHH2, injected with dsCHH2. (B) The expression level of $\angle v G C$ after injection with $r C H H s$. (C) Silencing efficiency on $\angle v G C$ using different dosage of dsRNA. (D) Expression changes of $\angle v I A G$ after LvGC knockdown. PBS, injected with PBS; rCHH1, injected with rCHH1; rCHH2, injected with rCHH2; dsEGFP, injected with dsEGFP; dsGC, injected with dsGC. Expression levels of target genes were detected in three replicates. Significant differences of the gene expression levels between two treatments were shown with a star $(*)$ at $P<0.05$ or two stars $\left({ }^{* *}\right)$ at $P<0.01$.

down-regulated by 24.2 and 30.3\%, respectively (Figure 8A). Then, the transcriptional level of $L v G C$ was detected after rCHHs injection. As shown in Figure 8B, the transcriptional level of $L v G C$ in cephalothorax was up-regulated by about $40 \%$ while no obvious change in eyestalk after injection of $\mathrm{rCHH} 1$. After injection of $\mathrm{rCHH} 2$, the expression levels of $L v G C$ were significantly increased by about 60 and $44 \%$ in eyestalk and cephalothorax, respectively.

Yeast two-hybrid assay was then performed to further investigate whether there were interactions between $\mathrm{LvCHHs}$ and LvGC. When the positive plasmids combination pGBKp53 and pGAD-T antigen were co-transformed into yeast cells, the reporter gene was activated and the colonies turned blue (Figures 9A,B, zone 1). When pGBK-CHH1 and pGAD-LvGC plasmids or pGBK-CHH2 and pGAD-LvGC were co-expressed in yeast cells, the colonies turned lighter blue (Figures 9A,B, zone 2). In self-activation and negative controls, the reporter gene was not activated and no blue signal was detected (Figures 9A,B, zones 3-5).

In order to know whether $L v G C$ could also influence the expression of $L v I A G$, the expression level of $L v I A G$ was detected after silencing of $L v G C$. When the expression level of $L v G C$ was knocked-down by 53\% (Figure 8C), the transcriptional level of $L v I A G$ was up-regulated by $78 \%$ (Figure $8 D$ ). These results suggested that LvGC was the putative receptor of LvCHH1 and
$\mathrm{LvCHH} 2$, and it could also show inhibitory effect, like LvCHH1 and $\mathrm{LvCHH} 2$, on the expression of LvIAG.

\section{DISCUSSION}

In crustacean, the "eyestalk-AG-testis" endocrine axis has been suggested to regulate male sexual differentiation (Khalaila et al., 2002). As the functional core of the axis, AG controls male sexual differentiation through secreting the sexual hormone IAG (Ventura and Sagi, 2012). We previously identified a male specific expressed IAG receptor, FcIAGR, from the shrimp F. chinensis (Guo et al., 2018). Knockdown of FcIAGR expression in a late developmental stage of shrimp retarded testis development, which provided evidence to the downstream of the "eyestalkAG-testis" endocrine axis. However, the upstream regulatory mechanism of the axis is still lack of reliable evidence.

The X-organ/sinus-gland (XO-SG) complex in the eyestalk is the major neuroendocrine system in crustacean suggested to be an upstream regulator in various endocrine axes. Sexual development related function of neurohormones mainly referred to eyestalk expressed $\mathrm{CHH}$ subfamily II members, which were considered as inhibitory factors on ovary development (de Kleijn et al., 1994; Gu et al., 2002; Treerattrakool et al., 2008; Vrinda et al., 2017) and IAG expression (Li et al., 2015). 

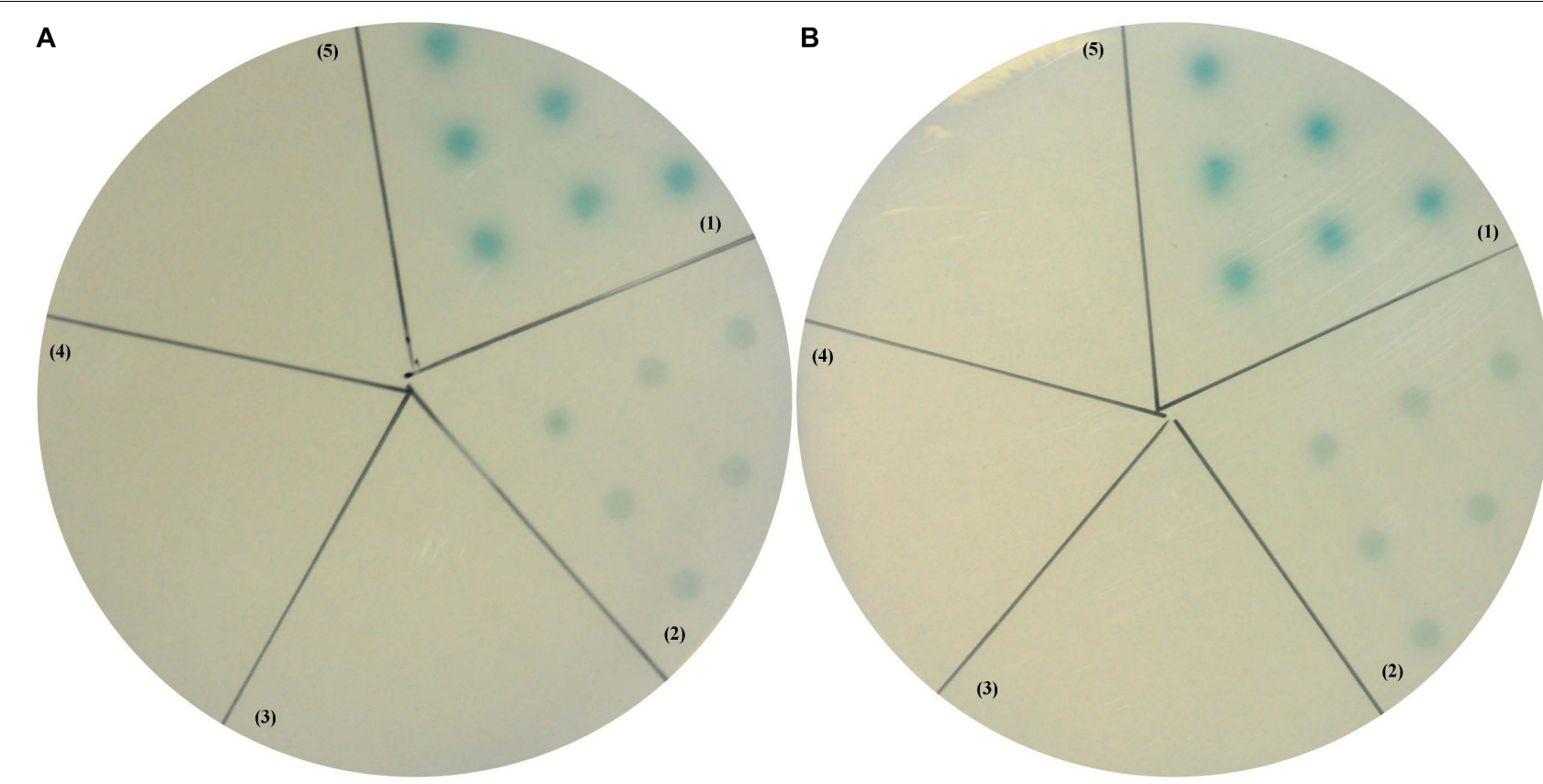

FIGURE 9 | Yeast two-hybrid assay between LvGC and LvCHH1 (A) or LvCHH2 (B). (1) A-B, pGBK-p53 and pGAD-T-antigen for positive control; (2) A, pGAD-LvGC and pGBK-LvCHH1 plasmids; B, pGAD-LVGC and pGBK-LVCHH2 plasmids; (3) A, pGAD-T7 and pGBK-LvCHH1 plasmids; B, pGAD-T7 and pGBK-LvCHH2 plasmids; (4) A-B, pGAD-LvGC and pGBK-T7 plasmids; (5) A-B, pGBK-Lam and pGAD-T-antigen for negative control.

On the other hand, CHH subfamily I members were usually deemed as hyperglycemic factors or osmo-regulators for their functions in regulating crustacean hemolymph glucose levels and ion transport (Chung et al., 2010). In L. vannamei, a striking expansion of $\mathrm{CHH}$ family genes was found in recent study and three major clades were identified in type I CHH peptides (Zhang et al., 2019). The type Ic clade peptides, which was penaeidspecific and had significant expansion in the genome, could regulate molting, reproduction, energetics, and ionic metabolism (Montagné et al., 2010; Zhang et al., 2019). This suggests that CHHs in L. vannamei diverse in expression patterns (such as co-expression and co-functionality) during regulating the same physiological process, and might also participate in other lesswell-studied physiological metabolism processes. $\mathrm{CHH}$ family genes were initially considered specifically expressed in eyestalk but were also detected in gut, pericardial organ and subesophageal ganglion in subsequent researches (Chang et al., 1999; Chung et al., 1999; Webster et al., 2000; Dircksen et al., 2001). The present $\mathrm{LvCHH} 1$ and $\mathrm{LvCHH} 2$ belong to $\mathrm{CHH}$ subfamily I members because they have the conversed CPRP domain, the processing signal KR and the amidation signal GK (Chan et al., 2003). They show sex-biased expression patterns both in eyestalks and gonads. The high expression levels of $\mathrm{LvCHH1}$ and $\mathrm{LvCHH} 2$ in male eyestalk rather than in female eyestalk indicated their involvement in male sexual development in shrimp. The higher level of LvCHH1 and LvCHH2 transcripts in ovary than in testis indicated that the two LvCHHs might also function in female reproduction.

As part of the "eyestalk-AG-testis" endocrine axis, the XOSG complex was found to have an inhibitory effect on AG development or $I A G$ expression. Eyestalk ablation in decapod crustaceans caused hypertrophy of the AG (Khalaila et al., 2002) and up-regulation of IAG transcripts (Chung et al., 2011; Li et al., 2015). The expression level of LvIAG was significantly up-regulated after unilateral eyestalk ablation. It indicates that the eyestalk expresses inhibitory factors that regulate $L v I A G$ expression. Similar increase in $L v I A G$ expression was achieved through knockdown of $\mathrm{LvCHH1}$ and $\mathrm{LvCHH}$, which was similar with the results in M. nipponense after silencing of VIH and MIH (Li et al., 2015). In further, injection of recombinant LvCHH1 and $\mathrm{LvCHH} 2$ protein inhibited the expression level of LvIAG. Collectively these results suggest that $\mathrm{LvCHH} 1$ and $\mathrm{LvCHH} 2$, which exhibit sex biased expression patterns in male and female eyestalks, are the inhibitory factors in shrimp eyestalks that play negatively regulatory activities on $L v I A G$ expression.

In lobster, membrane guanylate cyclase was proposed to be the receptor of $\mathrm{CHH}$ because $\mathrm{CHH}$ could elevate cyclic GMP (cGMP) levels and had no effect on soluble guanylate cyclase (Goy, 1990). This was further supported by evidence from Carcinus maenas, in which $\mathrm{CHH}$ could also increase cGMP levels (Chung and Webster, 2006). Sequence analysis and subcellular localization assay demonstrated that LvGC was a membrane guanylate cyclase. Gene knockdown, recombinant protein injection and yeast two-hybrid assay suggested unanimously that LvGC was the putative receptor for LvCHH1 and LvCHH2. Furthermore, LvGC also showed a sex-biased expression pattern in eyestalk which affected $L v I A G$ expression as well. These data indicated that LvGC had similar biological function to that of $\mathrm{LvCHH1}$ and $\mathrm{LvCHH} 2$ on male sexual development in shrimp. Taken all these data together, $\mathrm{LvCHH} 1, \mathrm{LvCHH} 2$, and $\mathrm{LvGC}$ are suggested to be 
important upstream components in shrimp "eyestalk-AG-testis" endocrine axis. However, no transcript of LvGC was detected in $\mathrm{AG}$, indicating that $\mathrm{LvCHH}$ might indirectly regulate the expression of $L v I A G$.

\section{CONCLUSION}

The present study characterized two $\mathrm{CHH}$ genes, $\mathrm{LvCHH1}$ and $\mathrm{LvCHH} 2$, and their putative receptor gene $\mathrm{LvGC}$ from L. vannamei. $\mathrm{LvCHH} 1$ and $\mathrm{LvCH} 2$ encode $\mathrm{CHH}$ subfamily I members and LvGC encodes a membrane-bound guanylate cyclase. They all show sex-biased expression patterns, in which they have higher expression level in male eyestalk than in female eyestalk, while they exhibit higher expression level in ovary than in testis. RNAi, recombinant protein injection and yeast twohybrid experiments show that LvGC is the receptor for LvCHH1 and LvCHH2. They all could inhibit the expression of LvIAG, suggesting that they are important regulators in male sexual development in shrimp. The present data provide new evidence to support the hypothesis that the "eyestalk-AG-testis" endocrine axis regulates male sexual development in crustaceans.

\section{REFERENCES}

Banzai, K., Ishizaka, N., Asahina, K., Suitoh, K., Izumi, S., and Ohira, T. (2011). Molecular cloning of a cDNA encoding insulin-like androgenic gland factor from the kuruma prawn Marsupenaeus japonicus and analysis of its expression. Fish. Sci. 77, 329-335. doi: 10.1007/s12562-011-0337-8

Böcking, D., Dircksen, H., and Keller, R. (2002). "The crustacean neuropeptides of the CHH/MIH/GIH family: structures and biological activities," in The Crustacean Nervous System, ed. K. Wiese (Berlin: Springer), 84-97. doi: 10.1007/ 978-3-662-04843-6_6

Chan, S. M., Gu, P. L., Chu, K. H., and Tobe, S. S. (2003). Crustacean neuropeptide genes of the $\mathrm{CHH} / \mathrm{MIH} / \mathrm{GIH}$ family: implications from molecular studies. Gen. Comp. Endocrinol. 134, 214-219. doi: 10.1016/s0016-6480(03)00263-6

Chang, E. S., Chang, S. A., Beltz, B. S., and Kravitz, E. A. (1999). Crustacean hyperglycemic hormone in the lobster nervous system: localization and release from cells in the subesophageal ganglion and thoracic second roots. J. Comp. Neurol. 414, 50-56. doi: 10.1002/(sici)1096-9861(19991108)414:1<50::aidcne $4>3.0$. co; $2-\mathrm{q}$

Chang, E. S., and Mykles, D. L. (2011). Regulation of crustacean molting: a review and our perspectives. Gen. Comp. Endocrinol. 172, 323-330. doi: 10.1016/j. ygcen.2011.04.003

Chung, J. S., Dircksen, H., and Webster, S. G. (1999). A remarkable, precisely timed release of hyperglycemic hormone from endocrine cells in the gut is associated with ecdysis in the crab Carcinus maenas. Proc. Natl. Acad. Sci. U.S.A. 96, 13103-13107. doi: 10.1073/pnas.96.23.13103

Chung, J. S., Manor, R., and Sagi, A. (2011). Cloning of an insulin-like androgenic gland factor (IAG) from the blue crab, Callinectes sapidus: implications for eyestalk regulation of IAG expression. Gen. Comp. Endocrinol. 173, 4-10. doi: 10.1016/j.ygcen.2011.04.017

Chung, J. S., and Webster, S. G. (2006). Binding sites of crustacean hyperglycemic hormone and its second messengers on gills and hindgut of the green shore crab, Carcinus maenas: a possible osmoregulatory role. Gen. Comp. Endocrinol. 147, 206-213. doi: 10.1016/j.ygcen.2006.01.002

Chung, J. S., Zmora, N., Katayama, H., and Tsutsui, N. (2010). Crustacean hyperglycemic hormone $(\mathrm{CHH})$ neuropeptidesfamily: functions, titer, and binding to target tissues. Gen. Comp. Endocrinol. 166, 447-454. doi: 10.1016/ j.ygcen.2009.12.011

Cronin, L. E. (1947). Anatomy and histology of the male reproductive system of Callinectes sapidus rathbun. J. Morphol. 81, 209-240.

\section{DATA AVAILABILITY STATEMENT}

The datasets generated for this study can be found in the NCBI Bankit accession numbers: MK732901, MK732902, and MK732903.

\section{AUTHOR CONTRIBUTIONS}

SL and FL designed the research. QG, SL, and XL performed the research. QG and SL analyzed the data. QG, SL, JX, RM, AS, and FL wrote the manuscript. All authors reviewed the manuscript.

\section{FUNDING}

This work was financially supported by the National Key Research and Development Program of China (2018YFD0900202), the Joint NSFC-ISF Research Program (31861143047), the China Agriculture Research System48 (CARS-48), and the ISF-NSFC Joint Research Program (Grant No. 2368/18).

de Kleijn, D. P., Sleutels, F. J., Martens, G. J., and Herp, F. (1994). Cloning and expression of mRNA encoding prepro-gonad-inhibiting hormone $(\mathrm{GIH})$ in the lobster Homarus americanus. FEBS Lett. 353, 255-258. doi: 10.1016/00145793(94)01055-2

Dircksen, H., Böcking, D., Heyn, U., Mandel, C., Chung, J. S., Baggerman, G., et al. (2001). Crustacean hyperglycaemic hormone ( $\mathrm{CHH}$ )-like peptides and $\mathrm{CHH}-$ precursor-related peptides from pericardial organ neurosecretory cells in the shore crab, Carcinus maenas, are putatively spliced and modified products of multiple genes. Biochem. J. 356, 159-170. doi: 10.1042/bj3560159

Foulks, N. B., and Hoffman, D. L. (1974). The effects of eyestalk ablation and B-ecdysone on RNA synthesis in the androgenic glands of the protandric shrimp, Pandalus platyceros Brandt. Gen. Comp. Endocrinol. 22, 439-447. doi: 10.1016/0016-6480(74)90018-5

Gao, Y., Zhang, X., Wei, J., Sun, X., Yuan, J., Li, F., et al. (2015). Whole transcriptome analysis provides insights into molecular mechanisms for molting in Litopenaeus vannamei. PLoS One 10:e0144350. doi: 10.1371/journal. pone. 0144350

Goy, M. F. (1990). Activation of membrane guanylyl cyclase by an invertebrate peptide hormone. J. Biol. Chem. 265, 20220-20227.

Gu, P. L., Tobe, S. S., Chow, B. K., Chu, K. H., He, J. G., and Chan, S. M. (2002). Characterization of an additional molt inhibiting hormone-like neuropeptide from the shrimp Metapenaeus ensis. Peptides 23, 1875-1883. doi: 10.1016/ s0196-9781(02)00178-x

Guo, Q., Li, S. H., Lv, X. J., Xiang, J. H., Sagi, A., Manor, R., et al. (2018). A Putative insulin-like androgenic gland hormone receptor gene specifically expressed in male Chinese shrimp. Endocrinology 159, 2173-2185. doi: 10.1210/en.201703253

Khalaila, I., Manor, R., Weil, S., Granot, Y., Keller, R., and Sagi, A. (2002). The eyestalk-androgenic gland-testis endocrine axis in the crayfish Cherax quadricarinatus. Gen. Comp. Endocrinol. 127, 147-156. doi: 10.1016/s00166480(02)00031-x

Lacombe, C., Grève, P., and Martin, G. (1999). Overview on the sub-grouping of the crustacean hyperglycemic hormone family. Neuropeptides 33, 71-80. doi: 10.1054/npep.1999.0016

Lawrence, A., Green, S., and Chung, J. S. (2017). Isolation and tissue distribution of an insulin-like androgenic gland hormone (IAG) of the male red deep-sea crab, Chaceon quinquedens. Mar. Drugs 15:E241. doi: 10.3390/md15080241

Li, F., Bai, H., Zhang, W., Fu, H., Jiang, F., Liang, G., et al. (2015). Cloning of genomic sequences of three crustacean hyperglycemic hormone superfamily 
genes and elucidation of their roles of regulating insulin-like androgenic gland hormone gene. Gene 561, 68-75. doi: 10.1016/j.gene.2015.02.012

Li, S. H., Li, F. H., Sun, Z., and Xiang, J. H. (2012). Two spliced variants of insulinlike androgenic gland hormone gene in the Chinese shrimp, Fenneropenaeus chinensis. Gen. Comp. Endocrinol. 177, 246-255. doi: 10.1016/j.ygcen.2012.04. 010

Liu, A., Liu, J., Liu, F., Huang, Y., Wang, G., and Ye, H. (2018). Crustacean female sex hormone from the mud crab Scylla paramamosain is highly expressed in prepubertal males and inhibits the development of androgenic gland. Front. Physiol. 9:924. doi: 10.3389/fphys.2018.00924

Manor, R., Weil, S., Oren, S., Glazer, L., Aflalo, E. D., Ventura, T., et al. (2007). Insulin and gender: an insulin-like gene expressed exclusively in the androgenic gland of the male crayfish. Gen. Comp. Endocrinol. 150, 326-336. doi: 10.1016/ j.ygcen.2006.09.006

Montagné, N., Desdevises, Y., Soyez, D., and Toullec, J. Y. (2010). Molecular evolution of the crustacean hyperglycemic hormone family in ecdysozoans. BMC Evol. Biol. 10:62. doi: 10.1186/1471-2148-10-62

Okuno, A., Hasegawa, Y., and Nagasawa, H. (1997). Purification and properties of androgenic gland hormone from the terrestrial isopod Armadillidium vulgare. Zool. Sci. 14, 837-842. doi: 10.2108/zsj.14.837

Okuno, A., Hasegawa, Y., Ohira, T., Katakura, Y., and Nagasawa, H. (1999). Characterization and cDNA cloning of androgenic gland hormone of the terrestrial isopod Armadillidium vulgare. Biochem. Biophs. Res. Commun. 264, 419-423. doi: 10.1006/bbrc.1999.1522

Rosen, O., Manor, R., Weil, S., Gafni, O., Linial, A., Aflalo, E. D., et al. (2010). A sexual shift induced by silencing of a single insulin-like gene in crayfish: ovarian upregulation and testicular degeneration. PLoS One 5:e15281. doi: 10.1371/journal.pone.0015281

Sagi, A., Cohen, D., and Milner, Y. (1990). Effect of androgenic gland ablation on morphotypic differentiation and sexual characteristics of male freshwater prawns, Macrobrachium rosenbergii. Gen. Comp. Endocrinol. 77, 15-22. doi: 10.1016/0016-6480(90)90201-v

Santos, E. A., and Keller, R. (1993). Crustacean hyperglycemic hormone $(\mathrm{CHH})$ and the regulation of carbohydrate metabolism: current perspectives. Comp. Biochem. Phys. A 106, 405-411. doi: 10.1016/0300-9629(93) 90234-u

Sroyraya, M., Chotwiwatthanakun, C., Stewart, M. J., Soonklang, N., Kornthong, N., Phoungpetchara, I., et al. (2010). Bilateral eyestalk ablation of the blue swimmer crab, Portunus pelagicus, produces hypertrophy of the androgenic gland and an increase of cells producing insulin-like androgenic gland hormone. Tissue Cell 42, 293-300. doi: 10.1016/j.tice.2010.07.003

Suzuki, S., and Yamasaki, K. (1997). Sexual bipotentiality of developing ovaries in the terrestrial isopod Armadillidium vulgare (Malacostraca, Crustacea). Gen. Comp. Endocrinol. 107, 136-146. doi: 10.1006/gcen.1997.6914
Treerattrakool, S., Panyim, S., Chan, S. M., Withyachumnarnkul, B., and Udomkit, A. (2008). Molecular characterization of gonad-inhibiting hormone of Penaeus monodon and elucidation of its inhibitory role in vitellogenin expression by RNA interference. FEBS J. 275, 970-980. doi: 10.1111/j.1742-4658.2008.06266. $\mathrm{x}$

Vázquez-Islas, G., Garza-Torres, R., Guerrero-Tortolero, D. A., and CamposRamos, R. (2014). Histology of the androgenic gland and expression of the insulin-like androgenic gland hormone precursor gene in the genital organ of pacific white shrimp Litopenaeus vannamei. J. Crust. Biol. 34, 293-299. doi: 10.1163/1937240x-00002232

Ventura, T., Manor, R., Aflalo, E. D., Weil, S., Raviv, S., Glazer, L., et al. (2009). Temporal silencing of an androgenic gland-specific insulin-like gene affecting phenotypical gender differences and spermatogenesis. Endocrinology 150, 1278-1286. doi: 10.1210/en.2008-0906

Ventura, T., and Sagi, A. (2012). The insulin-like androgenic gland hormone in crustaceans: from a single gene silencing to a wide array of sexual manipulation-based biotechnologies. Biotechnol. Adv. 30, 1543-1550. doi: 10 . 1016/j.biotechadv.2012.04.008

Vrinda, S., Jasmin, C., Sivakumar, K. C., Jose, S., Jose, B., Philip, R., et al. (2017). Regulating gonad inhibition and vitellogenin/vitellin induction in Penaeus monodon using mature GIH fusion protein and polyclonal antisera. Comp. Biochem. Phys. A 203, 167-178. doi: 10.1016/j.cbpa.2016.09.007

Webster, S. G., Dircksen, H., and Chung, J. S. (2000). Endocrine cells in the gut of the shore crab Carcinus maenas immunoreactive to crustacean hyperglycaemic hormone and its precursor-related peptide. Cell Tissue Res. 300, 193-205. doi: 10.1007/s004410000176

Wei, J., Zhang, X., Yu, Y., Huang, H., Li, F., and Xiang, J. (2014). Comparative transcriptomic characterization of the early development in Pacific white shrimp Litopenaeus vannamei. PLoS One 9:e106201. doi: 10.1371/journal.pone. 0106201

Zhang, X. J., Yuan, J. B., Sun, Y. M., Li, S. H., Gao, Y., Yu, Y., et al. (2019). Penaeid shrimp genome provides insights into benthic adaptation and frequent molting. Nat. Commun. 10:356. doi: 10.1038/s41467-018-08197-4

Conflict of Interest: The authors declare that the research was conducted in the absence of any commercial or financial relationships that could be construed as a potential conflict of interest.

Copyright (c) 2019 Guo, Li, Lv, Xiang, Manor, Sagi and Li. This is an open-access article distributed under the terms of the Creative Commons Attribution License (CC BY). The use, distribution or reproduction in other forums is permitted, provided the original author(s) and the copyright owner(s) are credited and that the original publication in this journal is cited, in accordance with accepted academic practice. No use, distribution or reproduction is permitted which does not comply with these terms. 